\title{
Speciation of anthropogenic emissions of non-methane volatile organic compounds: a global gridded data set for 1970-2012
}

\author{
Ganlin Huang $^{1}$, Rosie Brook ${ }^{2}$, Monica Crippa ${ }^{3}$, Greet Janssens-Maenhout ${ }^{3}$, Christian Schieberle ${ }^{1}$, Chris Dore ${ }^{2}$, \\ Diego Guizzardi $^{4}$, Marilena Muntean ${ }^{3}$, Edwin Schaaf ${ }^{3}$, and Rainer Friedrich ${ }^{1}$ \\ ${ }^{1}$ Institute of Energy Economics and Rational Energy Use (IER), Universität Stuttgart, Hessbruehlstr. 49a, \\ 70565 Stuttgart, Germany \\ ${ }^{2}$ Aether, Emissions Inventory Consultancy, Oxford Centre for Innovation, New Road, Oxford OX1 1BY, UK \\ ${ }^{3}$ European Commission, Joint Research Centre (JRC), Directorate for Energy, Transport and Climate, \\ Air and Climate Unit, Via E. Fermi 2749, 21027 Ispra (VA), Italy \\ ${ }^{4}$ Didesk Informatica, Verbania (VB), Italy \\ Correspondence to: Ganlin Huang (ganlin.huang@ier.uni-stuttgart.de)
}

Received: 25 January 2017 - Discussion started: 30 January 2017

Revised: 24 April 2017 - Accepted: 16 May 2017 - Published: 26 June 2017

\begin{abstract}
Non-methane volatile organic compounds (NMVOCs) include a large number of chemical species which differ significantly in their chemical characteristics and thus in their impacts on ozone and secondary organic aerosol formation. It is important that chemical transport models (CTMs) simulate the chemical transformation of the different NMVOC species in the troposphere consistently. In most emission inventories, however, only total NMVOC emissions are reported, which need to be decomposed into classes to fit the requirements of CTMs. For instance, the Emissions Database for Global Atmospheric Research (EDGAR) provides spatially resolved global anthropogenic emissions of total NMVOCs. In this study the EDGAR NMVOC inventory was revised and extended in time and in sectors. Moreover the new version of NMVOC emission data in the EDGAR database were disaggregated on a detailed sector resolution to individual species or species groups, thus enhancing the usability of the NMVOC emission data by the modelling community. Region- and source-specific speciation profiles of NMVOC species or species groups are compiled and mapped to EDGAR processes (detailed resolution of sectors), with corresponding quality codes specifying the quality of the mapping. Individual NMVOC species in different profiles are aggregated to 25 species groups, in line with the common classification of the Global Emissions Initiative (GEIA). Global annual grid maps with a resolution of $0.1^{\circ} \times 0.1^{\circ}$ for the period $1970-2012$ are
\end{abstract}

produced by sector and species. Furthermore, trends in NMVOC composition are analysed, taking road transport and residential sources in Germany and the United Kingdom (UK) as examples.

\section{Introduction}

Non-methane volatile organic compounds (NMVOCs) consist of a variety of chemical species which can give rise to increases in tropospheric ozone concentrations and the formation of secondary organic aerosols (EEA, 2015; Guenther et al., 2012; Piccot et al., 1992). Some NMVOC species are toxic substances and can cause direct damage to human health (Weichenthal et al., 2012). A number of regulations, e.g. the directive on ambient air quality and cleaner air for Europe (2008/50/EC), the industrial emissions directive (2010/75/EU), and the decopaint directive (2004/42/EC), limit the emissions of NMVOCs or the concentration of secondary pollutants, for example ozone (Theloke and Friedrich, 2007) and particulate matter. Due to the non-linear relationship between emissions of NMVOCs and concentrations of secondary pollutants formed in the atmosphere, chemical transport models (CTMs) are typically used to assess the effectiveness of potential air pollution control strategies and policies. Control strategies can take the form of abatement strategies or action plans, which lead to a re- 
duction in ambient air concentrations and the achievement of target thresholds. Given the reactive nature of NMVOCs in the atmosphere, it is important that CTMs simulate the chemical transformation of the different NMVOC species in the troposphere to the best extent possible. To serve as input for chemistry models, the bulk NMVOC emissions need to be disaggregated to give information on species (or species groups) on a sector-by-sector basis. This is because different NMVOC species vary significantly in their chemical features and thus in their impacts on ozone and secondary organic aerosol formation. Whilst it is possible to consider the atmospheric chemistry of individual species, it is more practical for chemistry models to use species groups, which contain species similar in chemical structure or reactivity.

Determining and compiling NMVOC speciation profiles has attracted increasingly more scientific interest ( $\mathrm{Li}$ et al., 2014; Liu et al., 2008; Passant, 2002; Schultz et al., 2007; Theloke and Friedrich, 2007). However, all these studies have limited scope with regard to coverage in emission sources, species, or target regions. In addition, these studies typically include speciation profiles that do not match the level of sectorial disaggregation at which total NMVOC emissions are typically reported in emission inventories. It is therefore challenging to collect NMVOC speciation profiles for different sources and regions and to map them to existing emission inventories. However, undertaking this task provides information on the species composition of total NMVOC emissions data, which would serve as input data for CTMs and related health impact assessments.

NMVOC emissions are typically reported in national emission inventories as total NMVOCs rather than individual species or species groups. Although data exist on the emission of individual species, it is not a reporting requirement under international conventions and therefore is difficult to collate. Generally, data at individual or grouped NMVOC level are provided by taking total NMVOC emissions of different emission sources from existing emission inventories and then applying speciation profiles. These speciation profiles represent the share of different NMVOC species, or species groups within the total NMVOC emissions. The occurrence and magnitude of individual species can vary considerably depending on the emission source, and it is therefore necessary to collate speciation profiles that are sourceand fuel-specific. In addition, NMVOC speciation profiles are expected to vary on a geographical basis, caused by differences in fuel quality, combustion technologies, and endof-pipe control measures.

The Emissions Database for Global Atmospheric Research (EDGAR) provides spatially resolved global anthropogenic emissions of greenhouse gases and air pollutants. The total NMVOC emissions of EDGARv4.3.2 are reported (http://edgar.jrc.ec.europa.eu/overview.php?v=432), with no information on subdivisions into NMVOC species or species groups. This study updates the NMVOCs and disaggregates (speciate) NMVOC emission data in the EDGAR database to individual species or species groups on the same sector resolution as the total NMVOCs. Thus, the usability of the EDGAR data by the modelling community may be enhanced.

Region- and sector-specific speciation profiles are developed and provided. The most appropriate speciation profile for each EDGAR process (category of emission sources) is identified and mapped at a subsector level for different regions. The species structure and different speciation profiles are unified by aggregating individual NMVOC species to species groups, according to their chemical structure and reactivity. Combining total NMVOC emissions and speciation profiles, speciated NMVOC emissions by country and global $0.1^{\circ} \times 0.1^{\circ}$ grid maps for different processes are generated, from which trends in NMVOC composition are assessed. Quality assessment of the generated data sets is performed. A comparison with other speciated NMVOC emission inventory data is also conducted and discussed.

\section{Methodology and data}

Our general approach is as follows: we start with a systematic literature review, searching for speciation profiles from regional measurements and databases, and apply the available information to split the new version of the total NMVOC emissions from the EDGAR inventory (Janssens-Maenhout et al., 2017) into individual species, which are then lumped into 25 species groups (Olivier et al., 1996) as proposed within the Global Emission Inventory Activity (GEIA). Finally, global grid maps from 1970 to 2012 are developed at $0.1^{\circ} \times 0.1^{\circ}$ resolution for different sectors and species groups.

\subsection{Revised total NMVOC emissions of EDGAR}

The NMVOC emissions described in this work refer to the EDGARv4.3.2 data set, which includes annual emissions for 228 countries from the year 1970 until 2012. All anthropogenic activities have been grouped into the following emission sectors: power generation (IPCC_1996 categories $1 \mathrm{~A}$ and $1 \mathrm{~B})$, combustion for manufacturing industry (IPCC_1996 code 1A2), energy for buildings (IPCC_1996 code 1A4), road transportation including evaporative emissions for gasoline-related fuels (IPCC_1996 code 1A3b), transformation industry (IPCC_1996 codes $1 \mathrm{~A} 1 \mathrm{c}+1 \mathrm{~A} 5 \mathrm{~b} 1+1 \mathrm{~B} 1 \mathrm{~b}+1 \mathrm{~B} 2 \mathrm{a} 6+1 \mathrm{~B} 2 \mathrm{~b} 5+2 \mathrm{C} 1 \mathrm{~b}), \quad$ fugitive emissions from fuel exploitation (IPCC_1996 codes $1 \mathrm{~B} 1 \mathrm{a}+1 \mathrm{~B} 2 \mathrm{a} 1+1 \mathrm{~B} 2 \mathrm{a} 2+1 \mathrm{~B} 2 \mathrm{a} 3+1 \mathrm{~B} 2 \mathrm{a} 4+1 \mathrm{~B} 2 \mathrm{c}), \quad$ process emissions during production and application including the production of chemicals, paper, food, iron and steel production and solvent use (IPCC_1996 codes 2+3), oil refineries (IPCC_1996 codes 1A1b+1B2a5), agricultural waste burning (IPCC_1996 code 4F), shipping including both domestic and international shipping (IPCC_1996 codes 1A3d+1C2), railways, pipelines and off-road transport (IPCC_1996 code 
1A3c+1A3e), fossil fuel fires (IPCC_1996 code 7A), solid waste and wastewater (IPCC_1996 code 6), and aviation differentiating between climbing and descent, cruise, landing, take-off, and supersonic (IPCC_1996 code 1A3a). No large-scale biomass burning emissions are estimated in the current work.

EDGAR activity data were mainly retrieved from the IEA energy statistics (IEA, 2014) for the fuel consumption, from the commodity statistics of UN STATS (2014) and the USGS (2014) for production processes, and from the FAO (FAOSTAT, 2014) for agriculture. Further details on activity data by sector can be found in JanssensMaenhout et al. (2017) and in Sect. S4 in the Supplement. NMVOC emission factors are consistent with the EMEP/EEA 2013 guidebook (EEA, 2013) for Europe, and scientific literature has been taken into account to introduce country- and region- specific information, while abatement measures are mainly implemented for the road transport sector (consistent with the Euro standards), for the production of chemicals (CHa-formaldehyde (methanal), total polyethylene, CHa-propylene glycol, total polystyrene), for power generation (auto-produced electricity and public electricity production from natural gas), and for landfills. Figure S1 of the Supplement shows the comparison of global NMVOC emissions by sector for the different EDGAR versions v4.2 (refer to http://edgar.jrc.ec.europa. eu/overview.php?v=42), v4.3.1 (refer to http://edgar.jrc.ec. europa.eu/overview.php?v=431), and $\mathrm{v} 4.3 .2$ (http://edgar.jrc. ec.europa.eu/overview.php? $\mathrm{v}=432$ ) for the most recent year (2008) available for all data sets.

In addition, Figs. S2 and S3 show the comparison of NMVOC emissions of EDGARv4.3.2 and the best estimates provided by the HTAP_v2.2 (Hemispheric Transport of Air Pollution) inventory for the year 2010 by HTAP sector and country (refer to Janssens-Maenhout et al. (2015) and http://edgar.jrc.ec.europa.eu/htap_v2/index.php). Focusing on European countries (see Fig. S4), detailed comparison by sector and country (identified by ISO codes) is also performed with officially reported EEA NMVOC emission inventories for the year 2010 (http://www.eea.europa.eu/dataand-maps/data/).

\subsection{Data sources of NMVOC speciation profiles}

A review of the available literature and databases applicable to NMVOC speciation profiles in different regions was undertaken. Theloke and Friedrich (2007) provide a database (Institute of Energy Economics and Rational Energy Use (IER) database) of 87 speciation profiles for Europe. The profiles distribute total NMVOC emissions of anthropogenic NMVOC sources across 305 single NMVOC species or species classes. The IER database is widely used for emission analysis and creating input data for atmospheric dispersion models in Europe (Coll et al., 2010; Kühlwein et al., 2002; Vautard, 2003). This database is used as the main data source for the profile mapping of Europe. The joint EMEP/EEA air pollutant emission inventory guidebook (EEA, 2013) provides very detailed documentation on a sectorial basis for a number of pollutants. The NMVOC speciation profiles for the road transport sector were extracted from the EMEP/EEA guidebook.

In the absence of a comprehensive and elaborated NMVOC profile database for Asia, NMVOC speciation profiles from local studies have been systematically collected and analysed for different sources, including solvent use (Lau et al., 2010; Wang, 2014; Yuan et al., 2010), transport (Cai and Xie, 2009; Fu, 2008; Lau et al., 2010; Lu, 2003; Wei et al., 2012), fuel burning (Cai et al., 2010; Lau et al., 2010; Liu et al., 2008; Wei et al., 2012), biomass burning (Cai et al., 2010; Li et al., 2009; Wei et al., 2008), petrochemical industry (Lau et al., 2010; Liu et al., 2008; Wei et al., 2012), coking (He et al., 2005; Jia et al., 2009; Wei et al., 2012), production and manufacturing industry (Cai et al., 2010; He et al., 2012; Klimont et al., 2002), and waste disposal (Klimont et al., 2002). Information on NMVOC speciation in Asia was generally available only for China or for single Chinese regions, e.g. Shanghai (Cai et al., 2010) or the Pearl River Delta (Chan et al., 2006). Given that China is the biggest NMVOC emitter in Asia and given the lack of data for other Asian countries, it is assumed that the speciation profiles collected for China are representative of Asia.

In North America, reference material is typically well coordinated and centralized at a national level by the United States Environmental Protection Agency (US EPA). The SPECIATE4.4 data set (Hsu et al., 2014), hereafter referred to as SPECIATE, is the most comprehensive data set available for North America, containing 1879 unique speciation profiles for volatile organic compound (VOC) emissions disaggregated to 1717 individual species from an extensive list of sources. NMVOC speciation profiles for North America were extracted from the SPECIATE database.

Local studies or measurements of NMVOC composition of emission sources of other regions (e.g. Africa, Latin America) are too limited to support the generation of local NMVOC speciation database. Given that the SPECIATE database is the most comprehensive data source and is already widely used in locations where local data are not available, in our study we used it as the data source of NMVOC profiles for these regions.

When screening NMVOC speciation profiles, we have given preference to existing databases built on a large amount of studies. Research and articles that have already been taken into account in the above-mentioned review paper and databases are not listed here.

\subsection{Compilation and mapping of speciation profiles}

Total NMVOC emissions from the EDGAR v4.3.2 emission inventory (http://edgar.jrc.ec.europa.eu/overview.php? 
$\mathrm{v}=432$ ) are speciated at country- and process-disaggregated levels.

NMVOC speciation profiles collected from the different databases and publications were mapped to all EDGAR process codes which were retrieved from the EDGAR v4.3.2 emission inventory. The first step in this approach was to match the EDGAR process codes for which there was an exact or similar match in the corresponding profile database, i.e. a match between both the source and fuel type (as shown in Table S1 in the Supplement). If an exact match was unavailable, fuel-specific speciation profiles were assigned to EDGAR process codes (Tables S2 and S3). This process was continued, assigning the best available matches in the profile data set to EDGAR processes (Table S4). In many cases this involved expert judgement determining the best available profile where no sector or fuel-specific profiles were present in the speciation profile data set. However, the expert judgement was guided by a detailed knowledge of the emission characteristics of different sources, allowing the best available matches to be made and providing a complete, gap-filled data set.

For processes where similar technologies are used in different regions (e.g. boilers, vehicles) and local profiles are not available, profiles from databases of other regions (e.g. SPECIATE database, IER database) were used for filling the gaps within the data set for a certain region (e.g. China). As for regions other than Europe, Asia, and North America, the mapping done using the SPECIATE database is suggested to be taken as a general estimation of source-oriented NMVOC composition.

Most of the available speciation profiles are fuel-oriented, e.g. for coal combustion processes, and do not always match the scope of the sector activities, e.g. energy industry. In order to show how well the assigned NMVOC profile matches the corresponding EDGAR process, codes indicating the level of the matching quality were assigned to each mapping (see Table 1). Six levels of mapping quality codes are defined, which not only indicate how specific a match is but also imply priorities of further improvement. A quality code of 1 to 4 is considered to be a relatively good match and representative of the EDGAR process. Quality codes 5 and 6 represent fuzzy matches due to the lack of process-specific profiles and are considered to be the priority areas for further improvement.

Table S1 presents examples of chemical processes for which an exact match was assigned with the profile database. The assigned profiles are specific to EDGAR source codes, and there is no differentiation in technology codes within these EDGAR processes. Table S2 presents an example of a profile that is considered to be representative of the EDGAR process but not an exact match; for example the profile of external combustion boiler is identified as the best available match to the public cogeneration process. In this case, a mapping quality code of 2 is assigned. Table S3 shows an example, where no differentiation of profiles for technology codes was possible. In this case, only biodiesel profiles for lightduty trucks are available in the profile database and have been applied to processes for buses and heavy-duty vehicles. These mappings are assigned with quality code 3 . Table $\mathrm{S} 4$ shows examples of profiles that are considered to be fuel-specific only (quality code 4), a general profile (quality code 5), and a fuzzy match (quality code 6), respectively.

\subsection{Species aggregation}

In order to integrate the NMVOC speciation data from different databases into EDGAR and to provide a data set with manageable and user-friendly size and structure, individual NMVOC species in speciation profiles are aggregated to groups. Individual species could be lumped into different chemical mechanisms following different mapping rules. A review and consultation with modellers and experts regarding NMVOC species aggregation mechanisms were conducted. It was decided to aggregate single NMVOC species to the 25 species groups proposed within GEIA, as detailed in Table 2 where a general molecular formula and the photochemical ozone creation potential (POCP) are also provided. POCP values were calculated through weighted averages of the values reported in Dore et al. (2006) for the 50 most significant NMVOC species reported in the UK. Given the limited data available, the assigned POCP values are considered to be an estimate and not an accurate representation of the GEIA groups.

Lists of all the unique species present in different databases (i.e. SPECIATE, IER database) were created. Each species was then assigned to one of the GEIA 25 species groups. The general NMVOC species grouping methodology suggested by Carter (2015) was taken. Where a species contains more than one functional group, priority was typically given to the suffix of the species name since this functional group is generally the most relevant for ozone formation. For example, trichlorobenzenes are assigned to "other aromatics" rather than "chlorinated hydrocarbons" as the suffix of the species name belongs to the aromatics group.

\subsection{Development of grid maps}

The EDGAR v4.3.2 speciated NMVOC emissions are available both as time series by sector and country (19702012) and as global grid maps by sector at the following website http://edgar.jrc.ec.europa.eu/overview.php? v=432_VOC_spec. Grid maps are available every 10 years from 1970 to 2000 and with annual resolution from 2000 to 2012. The analysis of NMVOC emission time series and 2010 speciated grid maps is presented in Sect. 3.1.

\section{Results}

A global data set providing information about NMVOC composition for the 25 NMVOC groups for each EDGAR pro- 
Table 1. The quality codes used to describe the quality of the match between the speciation profile and the EDGAR process.

\begin{tabular}{ll}
\hline Quality code & Description \\
\hline 1 & Well matched. \\
2 & Well matched; fuel differentiation not fully addressed (e.g. biogasoline vs. gasoline). \\
3 & Sector- and fuel-specific; technology not differentiated (e.g. transport data that are not specific to a vehicle type). \\
4 & Fuel-specific; sector and technology not differentiated. \\
5 & Catch all processes; a general profile that provides a best available match. \\
6 & Best profile available; not considered to be a specific match. \\
\hline
\end{tabular}

Table 2. List of GEIA 25 NMVOC groups with molecular formulae and Photochemical Ozone Creation Potential (POCP).

\begin{tabular}{|c|c|c|c|}
\hline GEIA ID & GEIA group & $\begin{array}{l}\text { Molecular } \\
\text { formula }\end{array}$ & $\begin{array}{r}\text { POCP } \\
\text { (based on Dore et al., 2006) }\end{array}$ \\
\hline voc1 & Alkanols (alcohols) & $\mathrm{C}_{n} \mathrm{H}_{2 n+1} \mathrm{OH}$ & 34.92 \\
\hline $\operatorname{voc} 2$ & Ethane & $\mathrm{C}_{2} \mathrm{H}_{6}$ & 12.30 \\
\hline voc3 & Propane & $\mathrm{C}_{3} \mathrm{H}_{8}$ & 22.12 \\
\hline $\operatorname{voc} 4$ & Butanes & $\mathrm{C}_{4} \mathrm{H}_{10}$ & 36.54 \\
\hline $\operatorname{voc} 5$ & Pentanes & $\mathrm{C}_{5} \mathrm{H}_{12}$ & 39.50 \\
\hline voc6 & Hexanes and higher alkanes & $\mathrm{C}_{n} \mathrm{H}_{2 n+2}(n \geq 6)$ & 44.15 \\
\hline $\operatorname{voc} 7$ & Ethene (ethylene) & $\mathrm{C}_{2} \mathrm{H}_{4}$ & 100.00 \\
\hline $\operatorname{voc} 8$ & Propene & $\mathrm{C}_{3} \mathrm{H}_{6}$ & 97.89 \\
\hline voc9 & Ethyne (acetylene) & $\mathrm{C}_{2} \mathrm{H}_{2}$ & 8.50 \\
\hline voc10 & Isoprenes & $\mathrm{C}_{5} \mathrm{H}_{8}$ & 109.20 \\
\hline voc11 & Monoterpenes & $\mathrm{C}_{10} \mathrm{H}_{16}$ & $109.20^{\mathrm{a}}$ \\
\hline $\operatorname{voc} 12$ & Other alk(adi)enes/alkynes (olefines) & $\mathrm{C}_{n} \mathrm{H}_{2 n-2}$ & 95.29 \\
\hline voc13 & Benzene (benzol) & $\mathrm{C}_{6} \mathrm{H}_{6}$ & 21.80 \\
\hline voc14 & Methylbenzene (toluene) & $\mathrm{C}_{7} \mathrm{H}_{8}$ & 63.70 \\
\hline $\operatorname{voc} 15$ & Dimethylbenzenes (xylenes) & $\mathrm{C}_{6} \mathrm{H}_{4}\left(\mathrm{CH}_{3}\right)_{2}$ & 107.41 \\
\hline voc16 & Trimethylbenzenes & $\mathrm{C}_{6} \mathrm{H}_{3}\left(\mathrm{CH}_{3}\right)_{3}$ & 129.86 \\
\hline $\operatorname{voc} 17$ & Other aromatics & $\mathrm{C}_{n} \mathrm{H}_{2 n-6}$ & 77.78 \\
\hline voc18 & Esters & $R-\mathrm{C}(=\mathrm{O}) \mathrm{O}-R^{\prime}$ & 20.68 \\
\hline voc19 & Ethers (alkoxy alkanes) & $R-\mathrm{O}-R^{\prime}$ & $12.44^{\mathrm{b}}$ \\
\hline $\operatorname{voc} 20$ & Chlorinated hydrocarbons & $\mathrm{CH}_{3} \mathrm{Cl}$ & 23.72 \\
\hline $\operatorname{voc} 21$ & Methanal (formaldehyde) & $\mathrm{CH}_{2} \mathrm{O}$ & 51.90 \\
\hline $\operatorname{voc} 22$ & Other alkanals (aldehyedes) & $R-\mathrm{CHO}$ & 64.10 \\
\hline $\operatorname{voc} 23$ & Alkanones (ketones) & $R-\mathrm{C}(=\mathrm{O})-R^{\prime}$ & 24.54 \\
\hline $\operatorname{voc} 24$ & Acids (alkanoic) & $R-\mathrm{C}_{n} \mathrm{H}_{n} \mathrm{COOH}$ & $12.44^{\mathrm{b}}$ \\
\hline $\operatorname{voc} 25$ & Other NMVOCs (HCFCs, nitriles, etc.) & NA & 12.44 \\
\hline
\end{tabular}

a Value was not available, has been assumed to be the same as "isoprenes". b Values not available, assigned the same value as "other". Notes: $R$ and $R^{\prime}$ denote functional groups. Where general formulae are not appropriate, the simplest molecular formula representing the group is provided. NA: not available.

cess from 1970 to 2012 was developed and integrated into the EDGAR database. The compiled NMVOC species emission time series (1970-2012) by IPCC sector (and their allocation to EDGAR processes) and country are available in overview tables (.xls) on the EDGAR website (http://edgar. jrc.ec.europa.eu/overview.php?v=432_VOC_spec).

\subsection{Species time series 1970-2012 and 2010 grid maps}

Over the past four decades, global NMVOC emissions increased from 119000 to $169000 \mathrm{kt}$, although different regional trends can be observed, as shown in Fig. 1. North
America and Europe halved their emissions from 1970 to 2012, while Africa, China, India, and the rest of Asia increased their emissions by factors of $2.9,2.5,2.2$, and 1.8, respectively. Nowadays, top emitter countries are Asia and Africa producing ca $65 \%$ of global NMVOCs, while North America and Europe contribute only to $14 \%$ (in comparison to 1970 when they contributed $37 \%$ of global NMVOC emissions). The reduction in American and European NMVOC emissions has happened mainly in the road transport sector (affecting both evaporative and combustion emissions) and residential combustion due to the implementation of reduction measures (e.g. Euro emission standards for vehicles) 


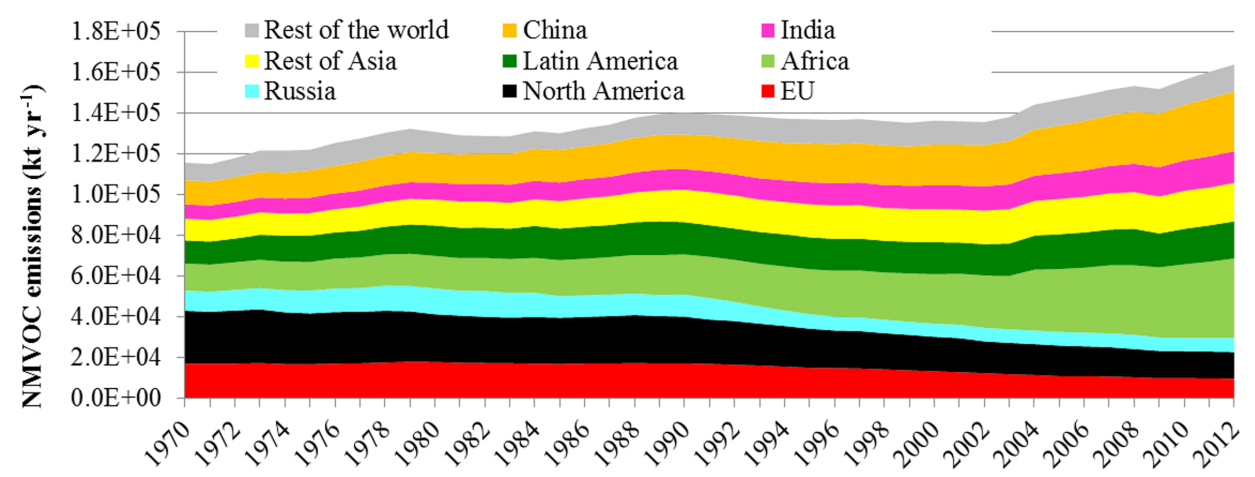

Figure 1. Global trend in NMVOC emissions by region.

combined with the use of cleaner fuels. Global NMVOC emissions are mainly produced by road transportation, residential combustion, transformation industry, fuel production and transmission, and solvent use, representing 16, 15, 18, 16 , and $12 \%$ of 2010 total NMVOC emissions, respectively.

Figure 2 presents an example of global grid maps obtained for a single NMVOC species of the EDGARv4.3.2 data set. As reported in Fig. 2, for 2010 we observe a significant reduction in methanal emissions, in particular over Europe, which can be attributed to the adoption of increasingly stringent Euro standards compared to the year 2000. A similar pattern is also observed for benzene emitted by the same sector.

Figures 3 and 4 represent 2010 total NMVOC grid maps for the residential and road transport sectors. In addition, the relative contribution of the NMVOC species grouped into eight main categories (refer to Table S5) for each sector is reported in the pie charts for major world regions.

The highest NMVOC emissions for the residential sector are observed in Africa (7.9 kt), China (5.2 kt), and India (4.3 kt) for 2010. For $201060 \%$ of global NMVOC emissions from the residential sector are attributed to aldehydes (grouped here as alkanals) mainly emitted from biomass combustion (refer to Fig. S5a); however, a different composition of NMVOC emissions is retrieved for different world regions, as shown in Fig. 3: the USA, Latin America, and Africa are characterized by a rather similar composition of residential emissions (alkanals, aromatics, and "other VOCs") partly reflecting the gap-filling procedure using the SPECIATE database. In addition to aromatics (dimethylbenzenes and benzene) and alkanals (aldehydes), EU residential emissions are characterized by alkenes (ethane) and alkynes. Chinese and Indian residential emissions are dominated by alkenes (ethane), alk(adi)enes/alkynes (ethyne and olefines), and other VOCs (e.g. ketones).

Similar to Fig. 3, Fig. 4 represents total and speciated NMVOC emissions for the road transport sector for 2010 , including both combustion and evaporative emissions. Latin America (5.1 kt), the USA (3.4 kt), and China (3.0 kt) are the top emitters for this sector, while Europe $(0.8 \mathrm{kt})$ is the low- est emitter due to the higher share of diesel vehicles compared to petrol engine vehicles (which are also subjected to evaporative emissions; see Fig. S5b). Overall, road transport emissions are dominated by $\mathrm{C} 2-\mathrm{C} 5$ and $\mathrm{C} 6+$ alkanes and aromatics (e.g. toluene); in addition contributions from alk(adi)enes/alkynes (olefins) and alkenes (ethane) are observed for Europe and the USA. Latin America is strongly dominated by alkanoic acids due to the higher share of biofuel used for road transport (refer to Fig. S5b).

\subsection{Case study on the impact of reduction measures on speciated NMVOC emissions for Germany and the UK}

The speciated NMVOC emissions data produced in this study allow the analyses of the trends in speciated NMVOC emissions by source and region. Control measures and emissions characteristics differ significantly among different sectors and regions. Preliminary analyses are conducted and presented for Germany and the UK with a focus on road transport and residential sources, considering data availability for national control strategies and significance of the impact.

\subsubsection{Case study on Germany}

The total NMVOC emissions from road transport in Germany decreased steadily since the 1990s as shown in Fig. 5a. The percentages of alkanes (propane, butanes, and pentanes) increased consecutively especially in recent years, while the proportion of aromatics decreased. These trends reflect the impacts of transport emission control strategies and the utilization of cleaner fuels in Germany. According to the EMEP/EEA air pollutant emission inventory guidebook for road transport (EEA, 2013), NMVOC emissions from closed-loop-catalyst (Euro I and later) gasoline fourstroke vehicles have a higher composition of alkanes and lower content of aromatics compared with that of conventional gasoline vehicles. The number of liquefied petroleum gas (LPG) vehicles in Germany increased from 40000 in 2006 to around 370000 in 2010 (KBA, 2010). The contents 

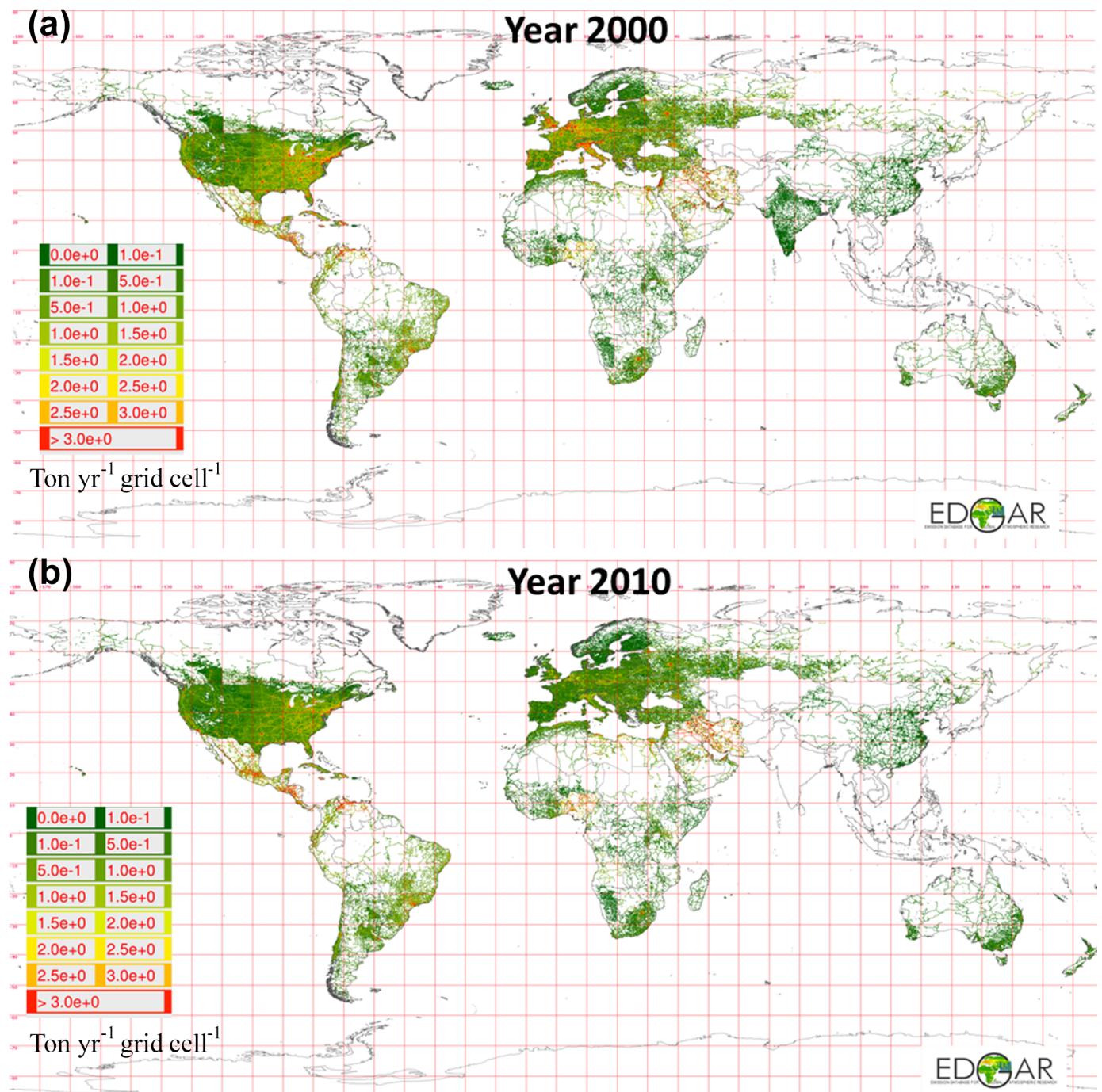

Figure 2. Comparison of 2000 and 2010 methanal emission grid maps for the road transport sector.

of alkanes (aromatics) in emissions from LPG vehicles are much higher (lower) than that from gasoline or diesel vehicles when comparing the corresponding profiles.

Residential NMVOC emissions in Germany decreased by more than $80 \%$ from 1986 to 2000 and then became relatively steady in recent years (Fig. 5b). The composition changes were however more substantial than those that occurred in the road transport sector. The percentages of alkenes and alkanal emissions increased, whilst the proportion of alkanes (C6+) and aromatics decreased over the considered time frame. These changes are related to the fuel shift from peat and coal to oil, gas, and solid biomass in the residential sector in Germany. Figure S6 presents the contribution of different types of fuel to NMVOC emissions of the residential sector in Germany from 1970 to 2012. NMVOC emissions from the combustion of peat accounted for over $50 \%$ of residential NMVOC emissions in Germany in the
1980 s, and decreased to $8 \%$ in 2010. Meanwhile the percentages of oil, gas, and biofuel (mainly primary solid biomass)related NMVOC emissions increased from $6 \%$ in 1970 to over $80 \%$ in 2010. NMVOC emissions from the combustion of peat have higher contents of alkanes (C6+) and aromatics (dimethylbenzenes) and lower contents of alkenes and alkanals compared with those of oil, natural gas, and solidbiomass combustion (Theloke and Friedrich, 2007).

With speciated NMVOC emissions data, the impacts of emission control policies by certain regions on the emission amount of specific NMVOC species as well as the NMVOC composition changes could be investigated and analysed.

\subsubsection{Case study on the United Kingdom}

The resulting data set for the UK is comparable with the UK's National Atmospheric Emission Inventory (NAEI). There are differences in the absolute values as this study was 


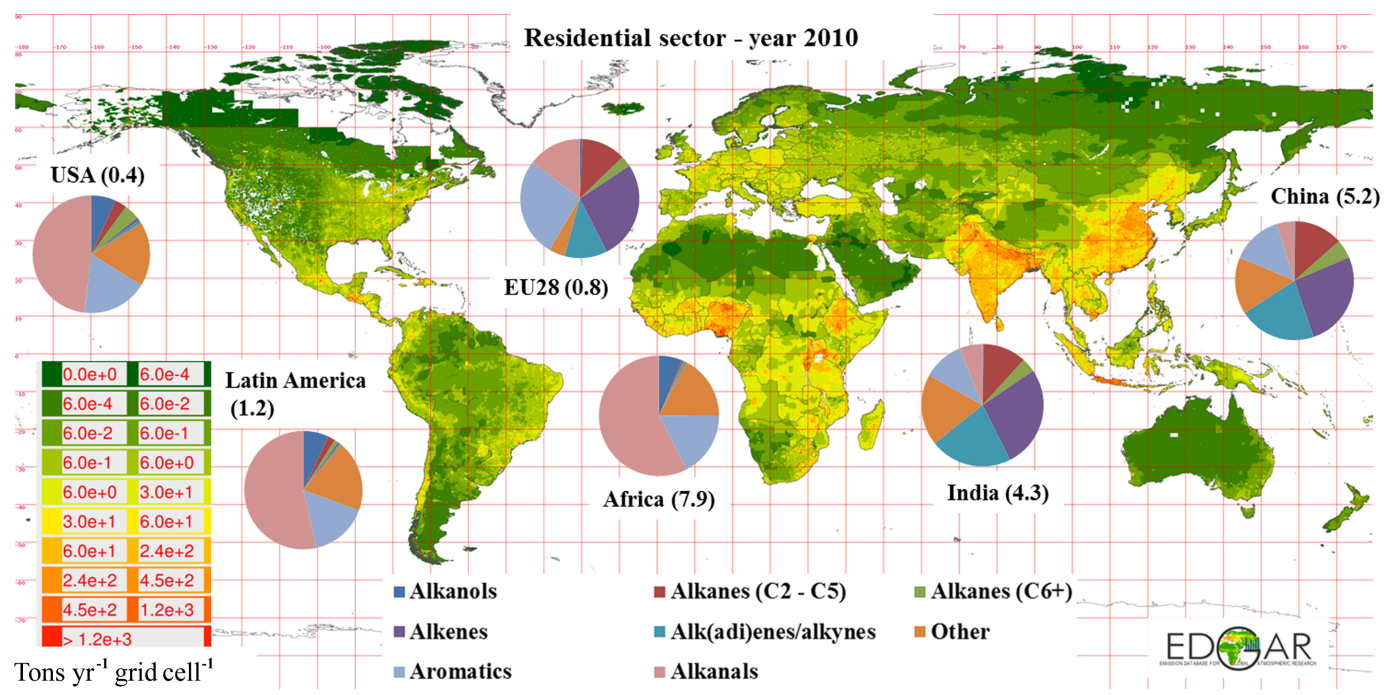

Figure 3. NMVOC emission grid map at $0.1 \times 0.1^{\circ}$ resolution from the residential sector in 2010 . The relative contribution of eight aggregated NMVOC species is reported in the pie charts for major world regions (numbers in brackets refer to total NMVOC emissions (in kilotons) for the residential sector for each region).

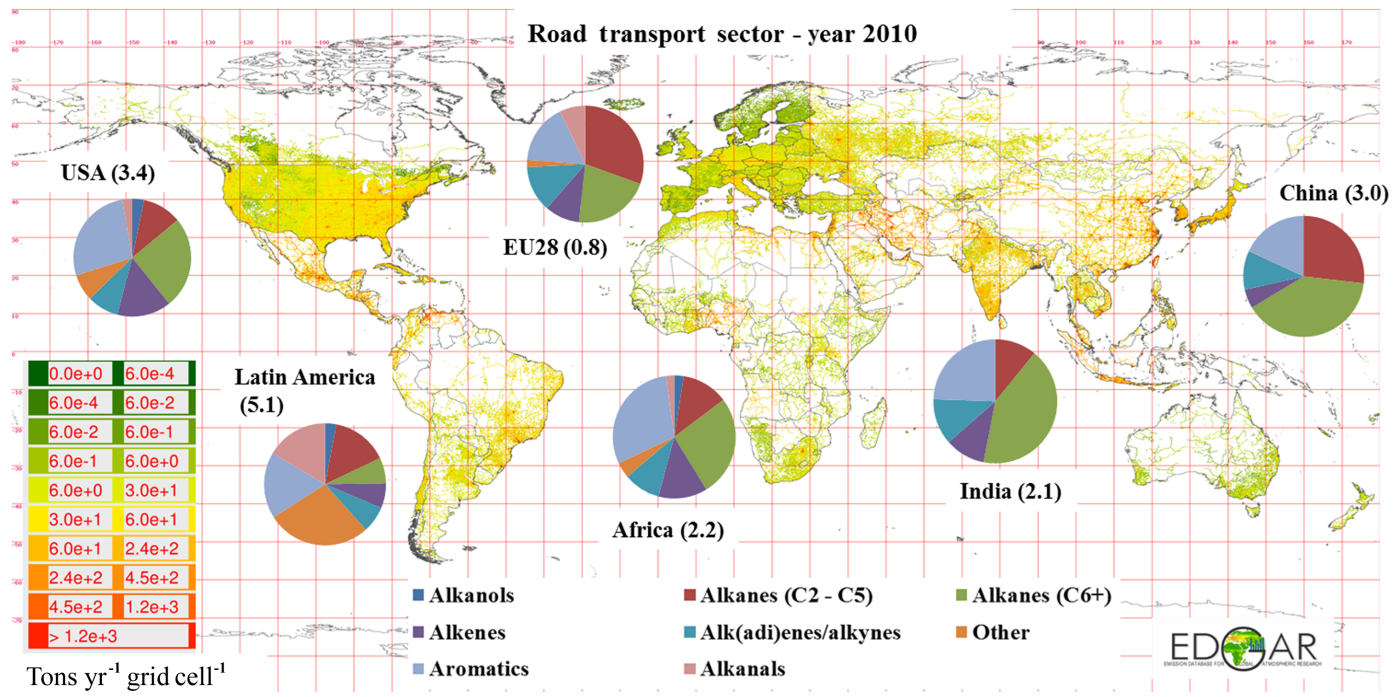

Figure 4. NMVOC emission grid map for the road transport sector in 2010. The relative contribution of NMVOC species is reported in the pie charts for major world regions (numbers in brackets refer to total NMVOC emissions (in kilotons) for the road transport sector for each region).

based on international data, due to a lack of available national data for this study. Higher NMVOC emissions are presented in the NAEI; however, the overall trends are the same. Similar to the trends in Germany (see Sect. 3.2.1), NMVOC emissions began to decline in 1990 for all major sources and decreased well below the Gothenburg Protocol Ceiling in 2010. Emissions in the UK have reduced by approximately $70 \%$ between 1990 and 2010; however, the rate of decline has decreased in recent years. This reduction has been driven by a number of key factors and legislation including the directive on industrial emissions (2010/75/EU), the solvents directive
(1999/13/EC), and the Convention on Long Range Transboundary Air Pollution (CLRTAP). In particular, industrial coatings, decorative paints, and printing are key sources of NMVOC emissions, and a reduction in the consumption of coatings and inks combined with the increasing regulation of solvent content of paints from the aforementioned directives has led to a reduction in emissions. NMVOC emissions from industrial combustion have declined since 1990 but not to the same extent as other pollutants. This because the majority of reductions in other air pollutants are due to fuel switching from coal and oil to gas, which are not the main sources of 
(a) Road transport sector

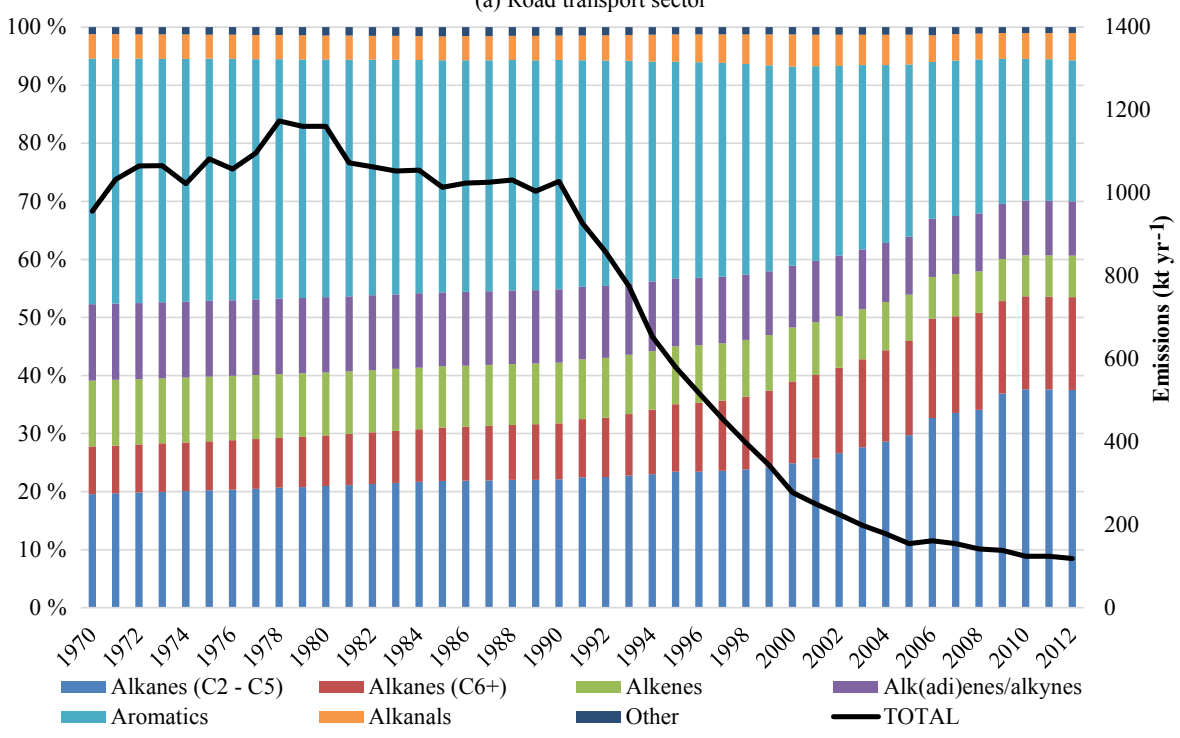

(b) Residential sector

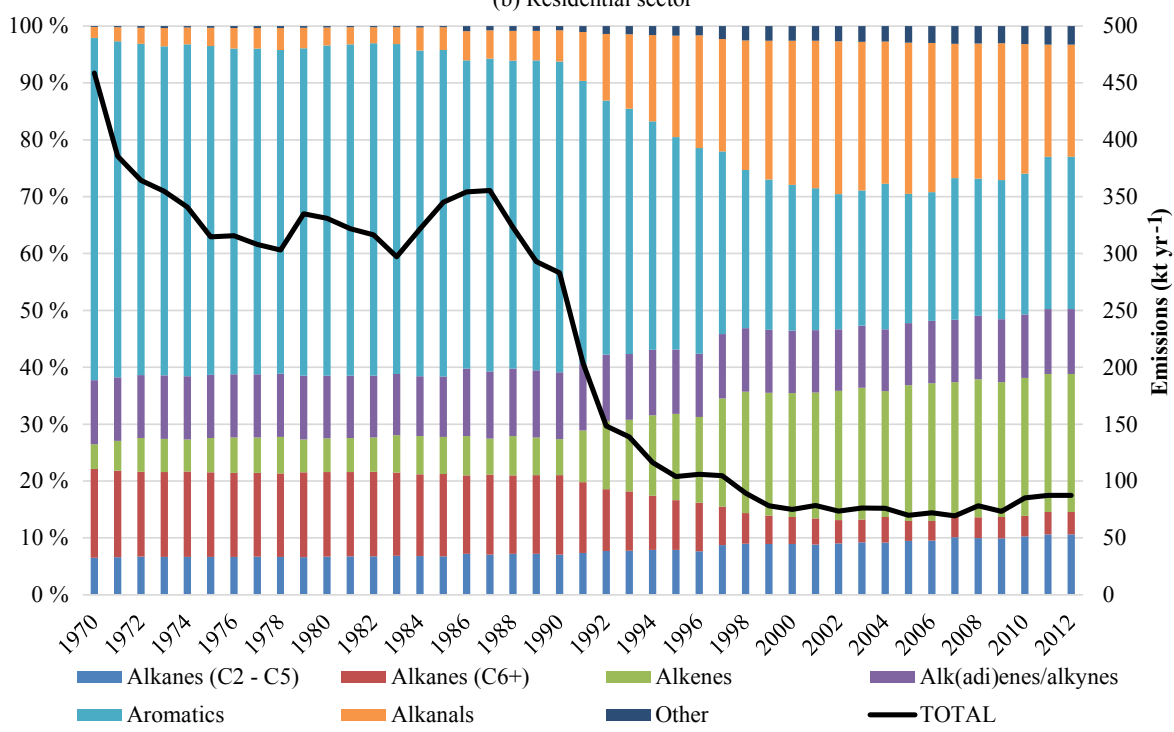

Figure 5. Total NMVOC emissions and their speciation for (a) the road transport sector and (b) the residential sector in Germany during 1970-2012.

NMVOC emissions. However, off-road vehicles and mobile machinery represent key sources for NMVOC emissions, and these emissions have decreased by approximately $40 \%$ since 1990 due to the introduction of units with diesel engines that comply with tighter regulation under the EU non-road mobile machinery emission directive (UK IIR, 2017).

For road transport emissions, the reduction in NMVOC emissions has been driven by the requirement for all new petrol cars to be fitted with three-way catalysts since 1989 and by fuel switching from petrol to diesel (UK IIR, 2017). Between 1990 and 2010 approximately $90 \%$ of NMVOC emissions from road transport are attributed to petrol vehicles; however, this contribution has been steadily declining over this period due to the increasing usage of diesel, LPG, and biogasoline in road transport. UK NMVOC emissions from petrol and diesel vehicles are presented in Fig. 6. Similar to the trends in Germany, the percentage contribution of short-chain alkanes from petrol emissions has increased since 1990, and the proportion of aromatics has declined.

\section{Quality assessment and data comparison}

\subsection{Quality assessment by region}

The availability of NMVOC speciation profiles varies among different sources. Whilst some detailed data are available for 
(a) Petrol vehicles

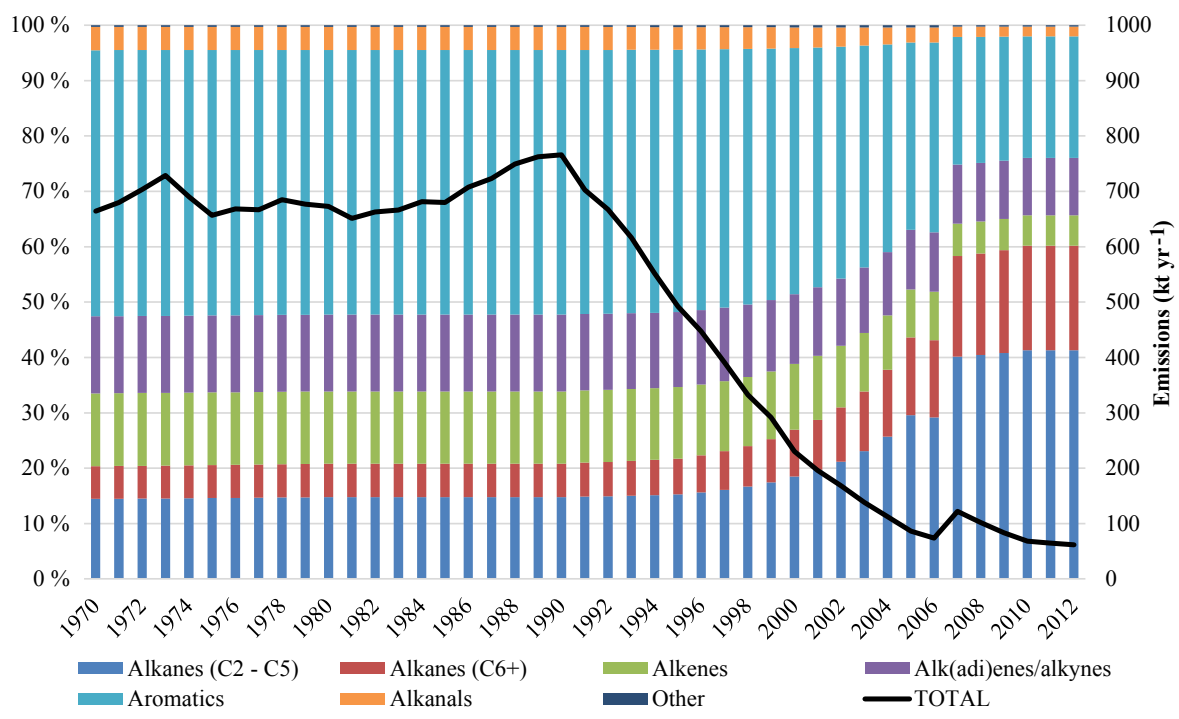

(b) Diesel vehicles

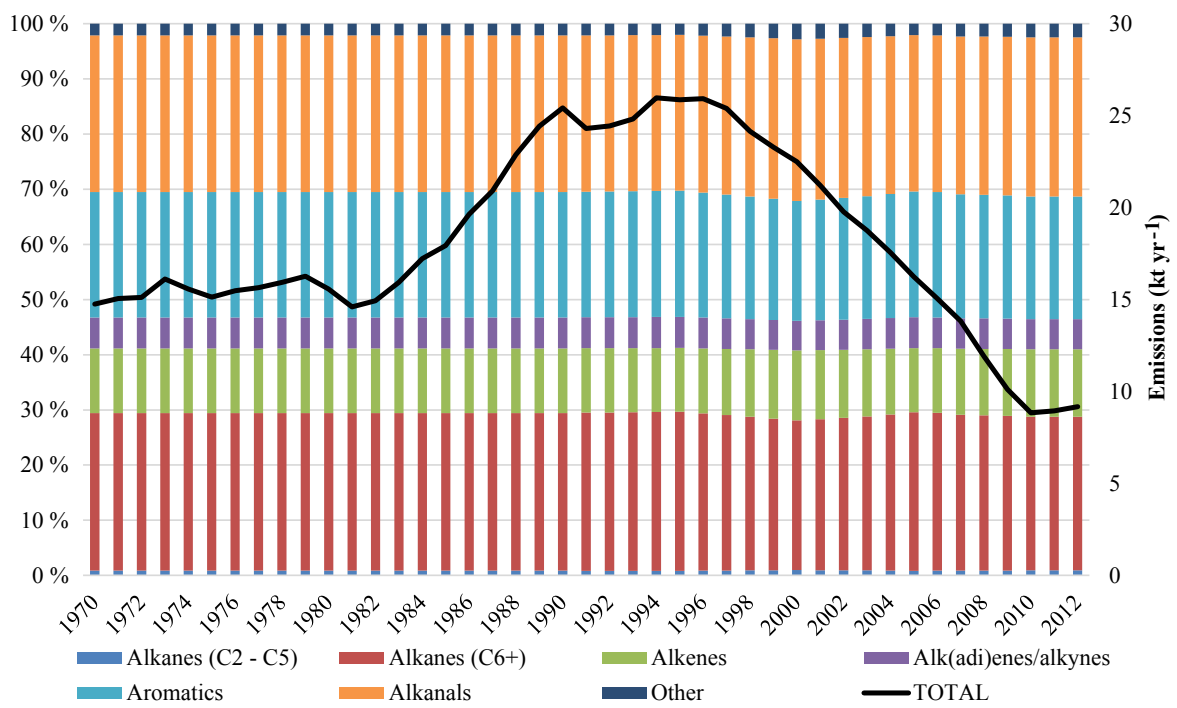

Figure 6. Total NMVOC combustion emissions and their speciation for (a) petrol vehicles and (b) diesel vehicles of the road transport sector in the UK during 1970-2012.

selected sources, the speciation profiles are not necessarily accompanied by information on either the accuracy or the general quality of the data. In addition, it is challenging to quantify the impact on uncertainty of some of the data handling steps (e.g. expert judgement in allocation of speciation profiles to particular EDGAR processes and the allocation of species to species groups). It was therefore considered that a qualitative approach was the most appropriate method for expressing uncertainties, by using "quality codes".

The use of "quality codes" is an approach commonly used (e.g. by the US EPA) when uncertainties are particularly large and/or difficult to quantify. Comparison of the types of profile matches that were made in this study using different databases (i.e. SPECIATE and IER data sets) led to the formation of six levels of quality codes (see Table 1). This was considered to be the best method to enable the quality of the assigned speciation profiles to be recognized, and to give a clear indication of the quality of the match between the EDGAR process and the assigned speciation profile.

Figure 7 provides a summary of the percentages of NMVOC emissions associated with each of the quality codes for Europe, China, and North America. Two years of data (2010 and 2000) are presented to reduce the bias caused by choosing a specific year. Overall, 42 (2010) and $55 \%$ (2000) of NMVOC emissions in Europe are attributable to the sources to which speciation profiles with quality code 1 (well matched) are mapped. For the emissions in China, 81 and $76 \%$ of NMVOC emissions are associated with fuel- 


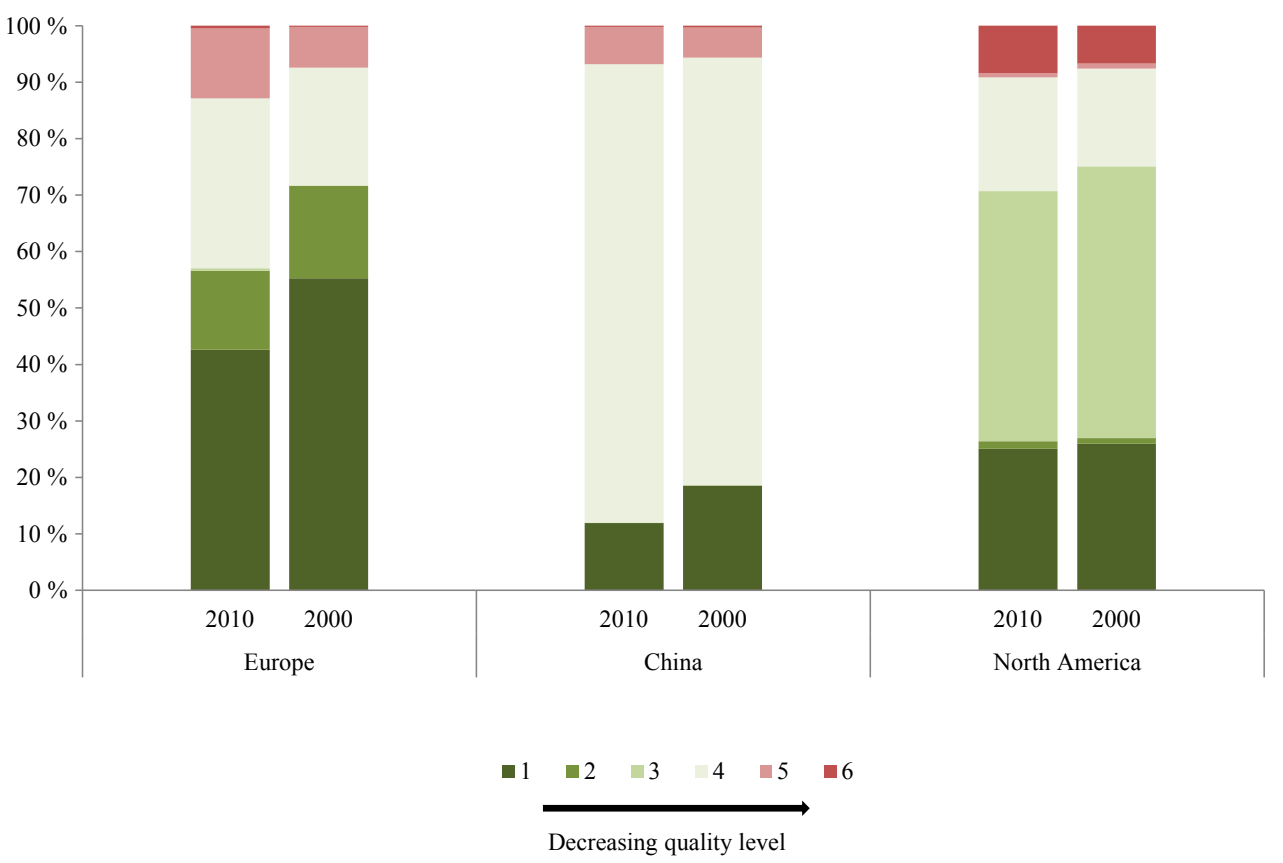

Figure 7. Percentages of NMVOC emissions associated with each quality code.

specific speciation profiles that are not sector-specific, i.e. quality code 4 , owing to poorer data availability in China. Overall, 44 (2010) and $48 \%$ (2000) of NMVOC emissions in North America are generated by the sources mapped with profiles of quality code 3 (sector- and fuel-specific). Percentages of qualities 5 and 6 related to NMVOC emissions in the three regions in both years are less than $13 \%$.

\subsection{Quality assessment by source}

The results are further disaggregated to different source groups as defined in the EDGAR database. Figures 8, 9, and 10 display the NMVOC emissions associated with each quality code of the EDGAR source groups in Europe, China, and North America, respectively, for 2010. Solvent use and road transport sectors were the largest NMVOC emission sources in Europe in 2010 according to the EDGAR v4.3.2 emission data. Solvent use is a comprehensive sector in the EDGAR emission inventory, which consists of solvents in, e.g., glues and adhesives, household products, and pesticides. The profile mapping quality of solvent use also varies among subsectors as shown in Fig. 8. Road transport processes mapped with well-matched (quality code 1) speciation profiles contribute to $96 \%$ of total NMVOC emissions of this source. This is primarily due to the good data quality of NMVOC speciation profiles extracted from the EMEP/EEA Guidebook (EEA, 2013). Up-to-date speciation profiles are provided for different vehicle types (e.g. light- or heavy-duty vehicles, passenger cars), fuel types (e.g. gasoline, diesel), and end-of-pipe technologies (e.g. pre- and post-Euro-I stan- dards). Chemicals and other production and solid-waste disposal are the NMVOC emission sources for which highquality speciation profiles are not available.

As a result of poorer data availability, the profile mapping quality for China is considered lower than that of Europe. Apart from solvent use and road transport, fuel production and residential and manufacturing industry were major NMVOC emission contributors in China in 2010 (see Fig. 9). Most of the NMVOC emissions of these three sources are mapped with fuel-specific speciation profiles (e.g. coal combustion, oil combustion). Residential sources contributed $20 \%$ to NMVOC emissions in China in 2010, which is consistent with a previous study ( $\mathrm{Li}$ et al., 2014). The production and use of other products and solid-waste disposal are sources which lack high-quality speciation profiles but have a relatively high contribution to total NMVOC emissions.

In North America, solvent use, road transport, and fuel production sources contributed almost $68 \%$ of total NMVOC emissions in 2010 (see Fig. 10). The speciation profiles from the SPECIATE database for road transport are mostly sectorand fuel-specific but not always with vehicle type specification (categorized as quality code 3 ). These profiles are related to $87 \%$ of road transport NMVOC emissions. Overall, $74 \%$ of NMVOC emissions from fuel production sources are mapped with fuel-specific speciation profiles (quality code 4). Overall, $90 \%$ of NMVOC emissions from non-road transport sources are mapped with speciation profiles with a quality code of 6 , resulting from the lack of profiles for shipping in the SPECIATE database. Good-quality speciation profiles for solid-waste disposal and food production 


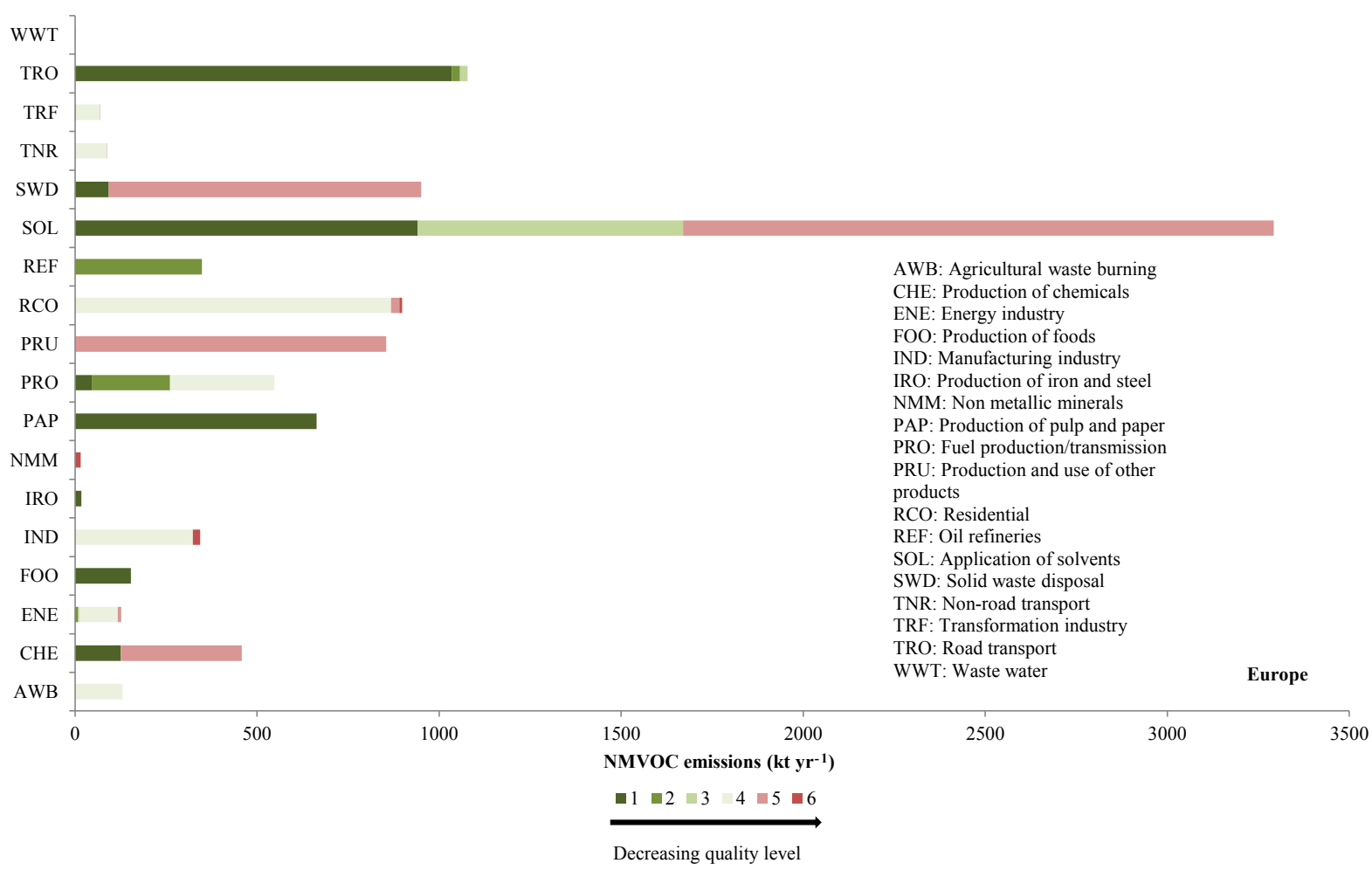

Figure 8. NMVOC emissions of different sources associated with each quality code in 2010 in Europe.

sources are also not available. However, given their relatively smaller contribution to total NMVOC emissions, the related impact on data quality is believed to be acceptable.

\subsection{Quality assessment by species group}

Figures 11, 12, and 13 show the emissions of 25 NMVOC species groups associated with each quality code for 2010 in Europe, China, and North America. In Europe, alkanols, other NMVOCs, and hexanes and higher alkanes are the dominant NMVOC species groups, which contributed 22.4, 10.4 , and $7.8 \%$ of total NMVOC emissions in 2010 , respectively (see Fig. 11). Solvent use contributed $80 \%$ of alkanol emissions in Europe in 2010. The profile for domestic solvent use shows that alkanols account for over $70 \%$ of total NMVOC emissions from this source (Theloke and Friedrich, 2007). Emissions of hexanes and higher alkanes are mainly from road transport (24\%), solvent use (20\%), and the production and use of other products $(15 \%)$. Overall, $40 \%$ of emissions of hexanes and higher alkanes are generated from processes mapped with well-matched speciation profiles (quality code 1).

As can be seen in Fig. 12, chlorinated hydrocarbons, hexanes and higher alkanes, and dimethylbenzenes were the most abundant NMVOC species groups in China in 2010. The abundance of aromatic hydrocarbons (dimethylbenzenes, methylbenzene, and benzene) and ethene emis- sions in China is also found by Li et al. (2014). The high proportions of chlorinated-hydrocarbon emissions found in this study are mainly from fuel production and transmission and from manufacturing industry. The high content of chlorinated hydrocarbons from coal combustion of these sectors in China is reported by local studies (Cai et al., 2010; Liu et al., 2008; Wei et al., 2012). Emissions of hexanes and higher alkanes mainly come from road transport (29\%) and fuel production and transmission $(23 \%)$. NMVOC emissions from motor cycles and crude oil refinery have a high content of hexanes and higher alkanes as shown by corresponding speciation profiles (Wei et al., 2012). Profile mappings classified as better than fuel-specific (quality code 4 ) are related to over $45 \%$ of total emissions of almost all the 25 species groups except for monoterpenes and acids, which only account for, in total, $0.1 \%$ of total NMVOC emissions in China. In North America (as shown in Fig. 13), alkanols, other NMVOCs, and hexanes and higher alkanes are the most important NMVOC species groups, which contributed 14.2, 13.8, and $11.5 \%$ of total NMVOC emissions, respectively, in 2010 . Over $65 \%$ of hexane and higher-alkane emissions were from road transport according to the data for North America in 2010. Hexanes and higher alkanes are the main NMVOC species of gasoline exhaust emissions (Hsu et al., 2014). Emissions of hexanes and higher alkanes from processes with sector- and fuel-specific (quality code 3) profile mapping account for $60 \%$ of total hexane and higher-alkane emissions. Overall, 


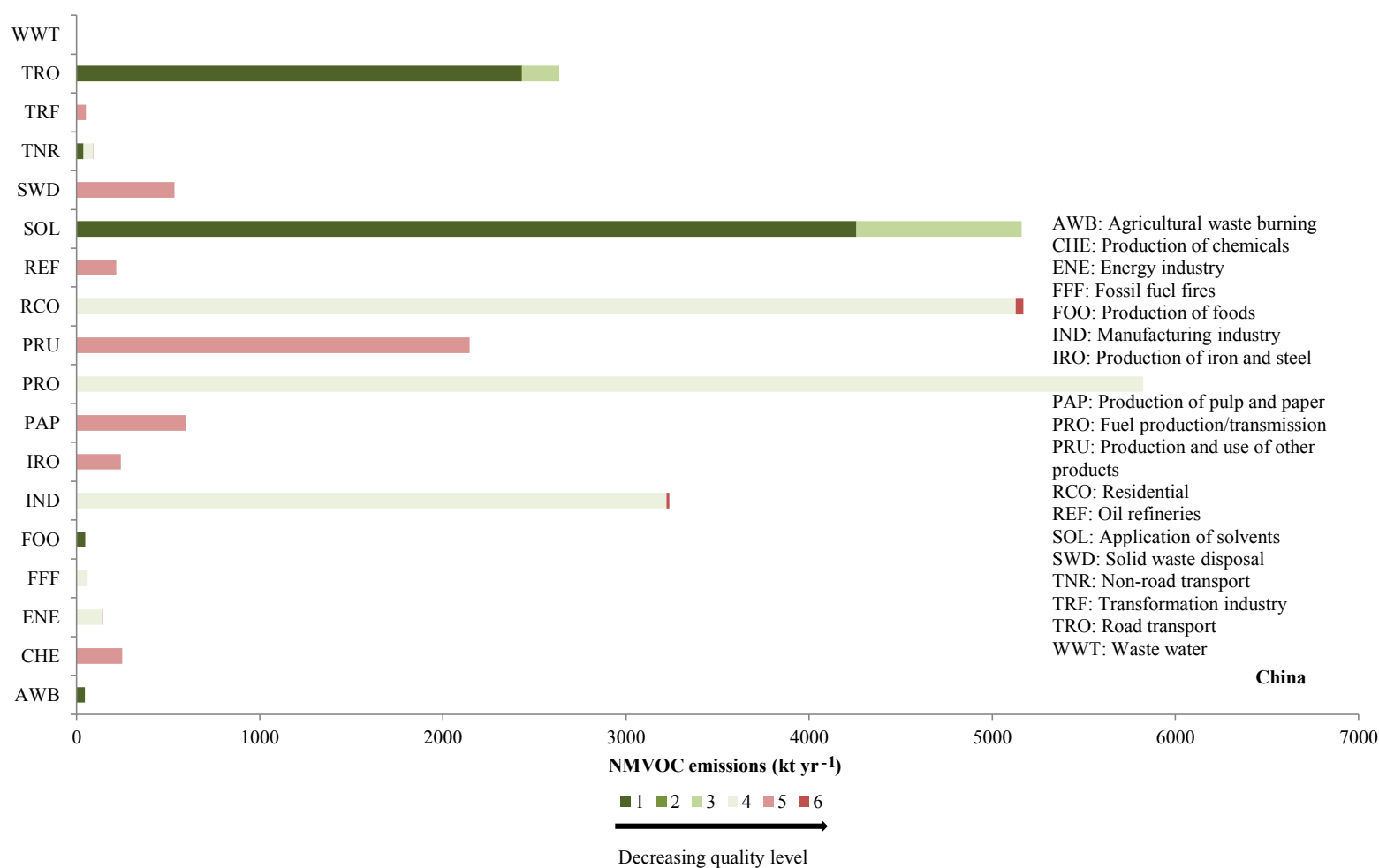

Figure 9. NMVOC emissions of different sources associated with each quality code in 2010 in China.

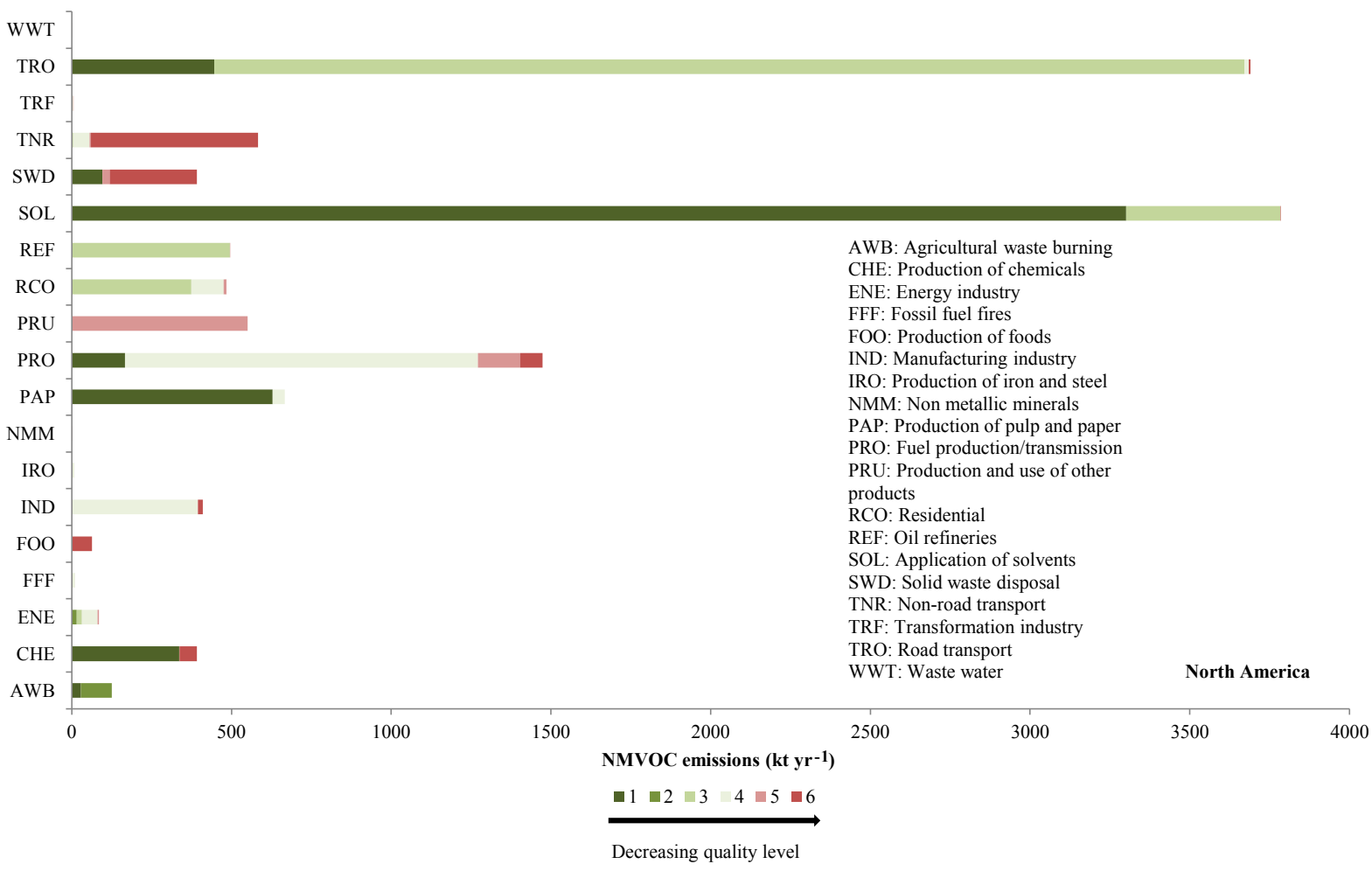

Figure 10. NMVOC emissions of different sources associated with each quality code in 2010 in North America. 


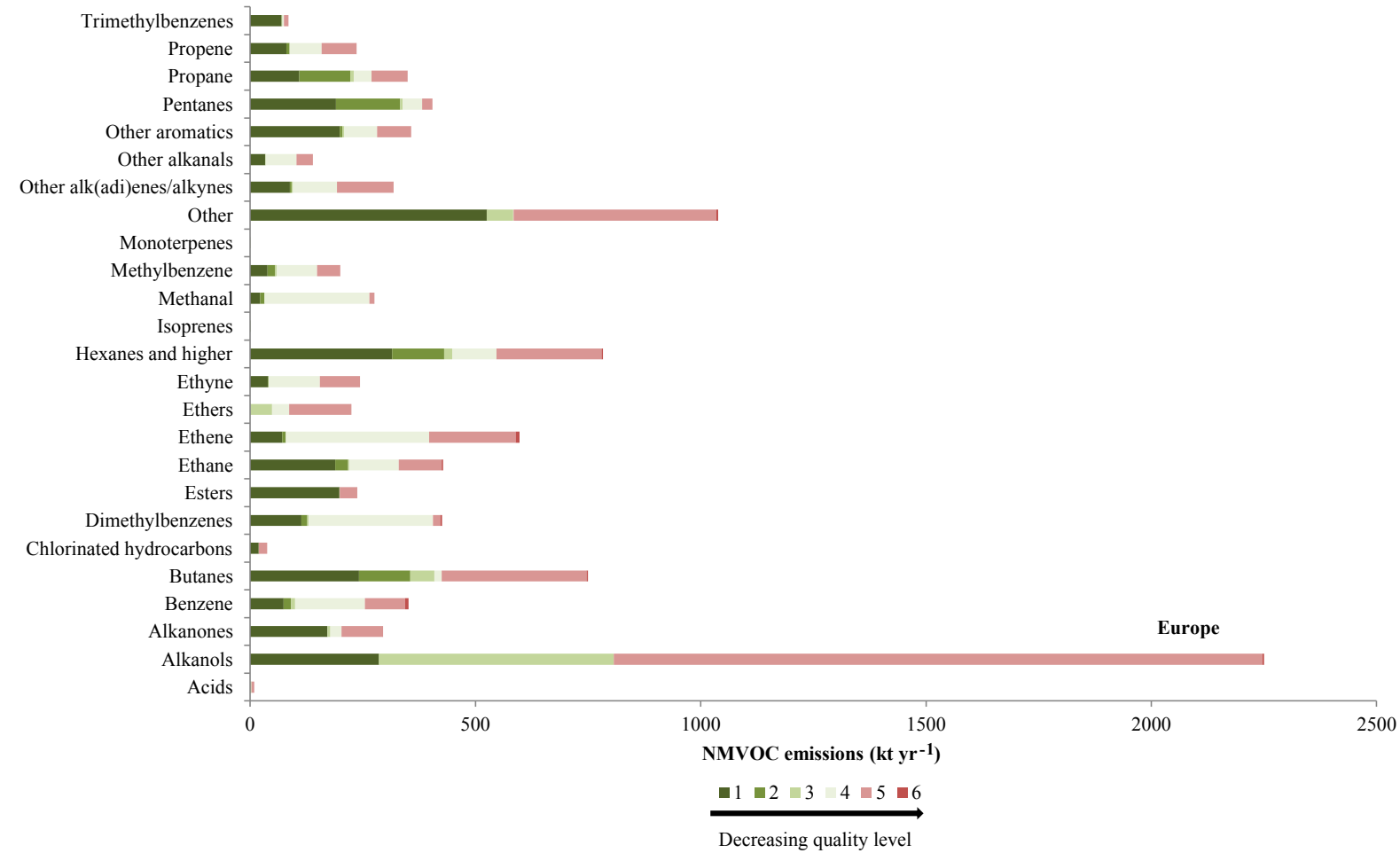

Figure 11. Emissions of 25 NMVOC groups associated with each quality code in 2010 in Europe.

$63 \%$ of emissions of other NMVOCs are related to processes mapped with well-matched (quality code 1) speciation profiles.

\subsection{Data comparison}

The EDGAR NMVOC speciation is compared with the RETRO (REanalysis of the TROposhperic chemical composition) emission inventory (Schultz et al., 2007), in which speciated NMVOC emission data are provided, although in a much coarser sectorial structure.

The RETRO emission inventory provides global gridded data sets for anthropogenic emissions covering the period from 1960 to 2000. NMVOC emissions are disaggregated to 25 NMVOC species groups and eight sectors. Each species group of NMVOC emissions of all sectors for Europe, China, and the United States is extracted from the RETRO emission grid maps. A matching between RETRO sectors and EDGAR sources is made (as shown in Table S7) based on sector definitions to prepare data from two inventories ready for comparison.

Figure 14 presents the comparison of NMVOC species composition of eight sectors between EDGAR and RETRO data sets for Europe, China, and the United States for the year 2000. It can be seen that the RETRO emission inventory generally shows the same or similar NMVOC composition across Europe (R_EU), China (R_CN), and the United States (R_US) for all the eight sectors, while the speciated
EDGAR NMVOC emission data (E_EU, E_CN, and E_US) gives a different picture on this issue. Regional variations in NMVOC composition could be seen across the investigated sectors from EDGAR emission data, which reflect the results of different fuel structures, technologies, and legislations among the three regions. Characteristics of NMVOC emissions composition of each sector in different regions could be better identified and analysed with the data sets produced in this study.

Generally, the RETRO data set agrees well with the EDGAR European data set, especially for fuel extraction and residential and transport sectors, which are the main sources of NMVOC emissions. It indicates that the RETRO data set may have used mainly European NMVOC profiles. For China, high contents of chlorinated hydrocarbon (classified as other NMVOCs in Fig. 14) emissions from fuel extraction and industrial and power generation sectors are recognisable from the EDGAR data set. Coal combustion is the main source of NMVOC emissions in those sectors in China. NMVOC speciation profiles of coal combustion sources collected from local studies (Cai et al., 2010; Liu et al., 2008; Wei et al., 2012) support this characteristic reflected by the EDGAR data set. For the United States, the EDGAR and RETRO data sets agree well with regard to the NMVOC composition of industrial and power generation emissions. The solvent use and transport sectors also have similar pictures. These four sectors contributed over $50 \%$ of 


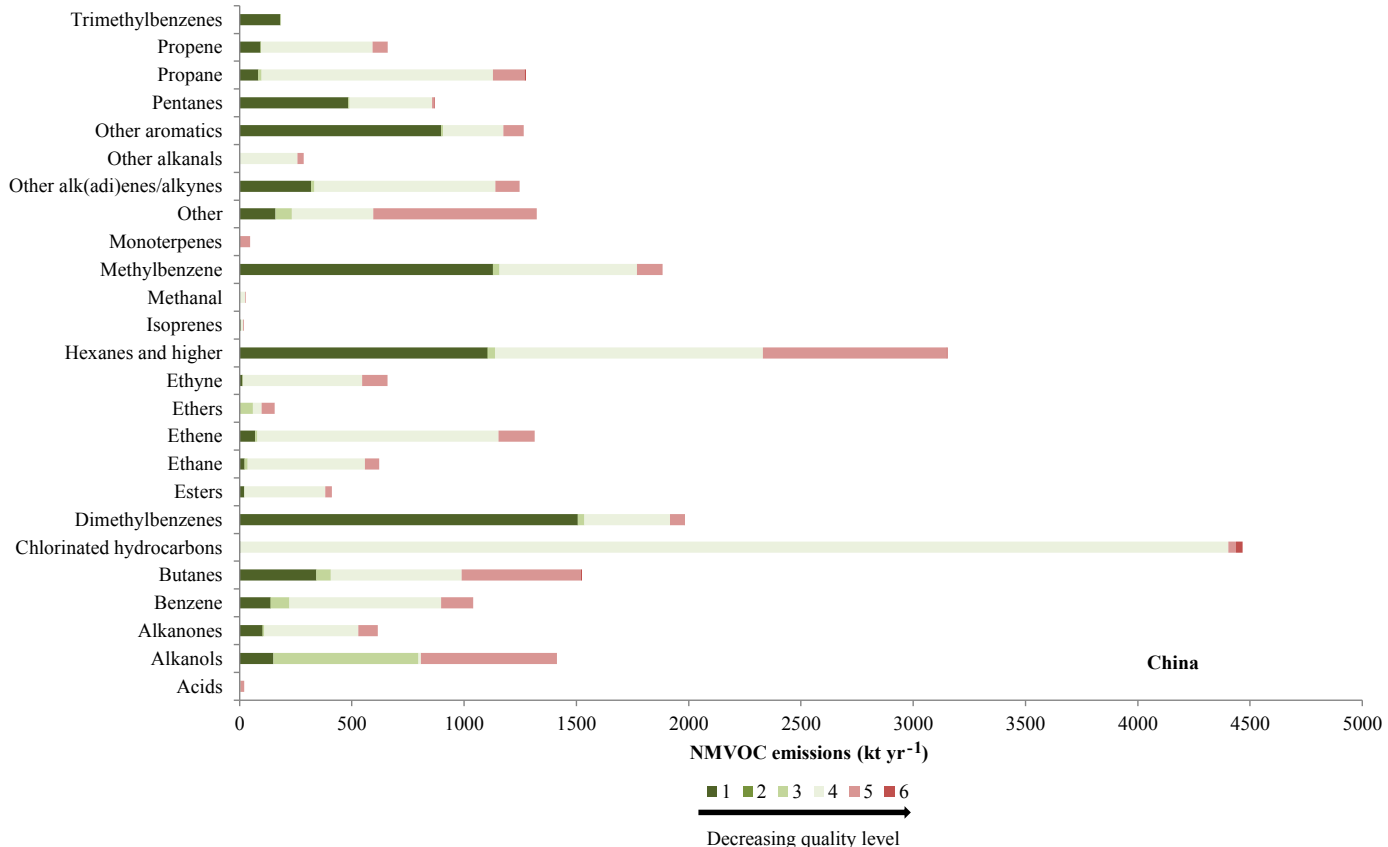

Figure 12. Emissions of 25 NMVOC groups associated with each quality code in 2010 in China.

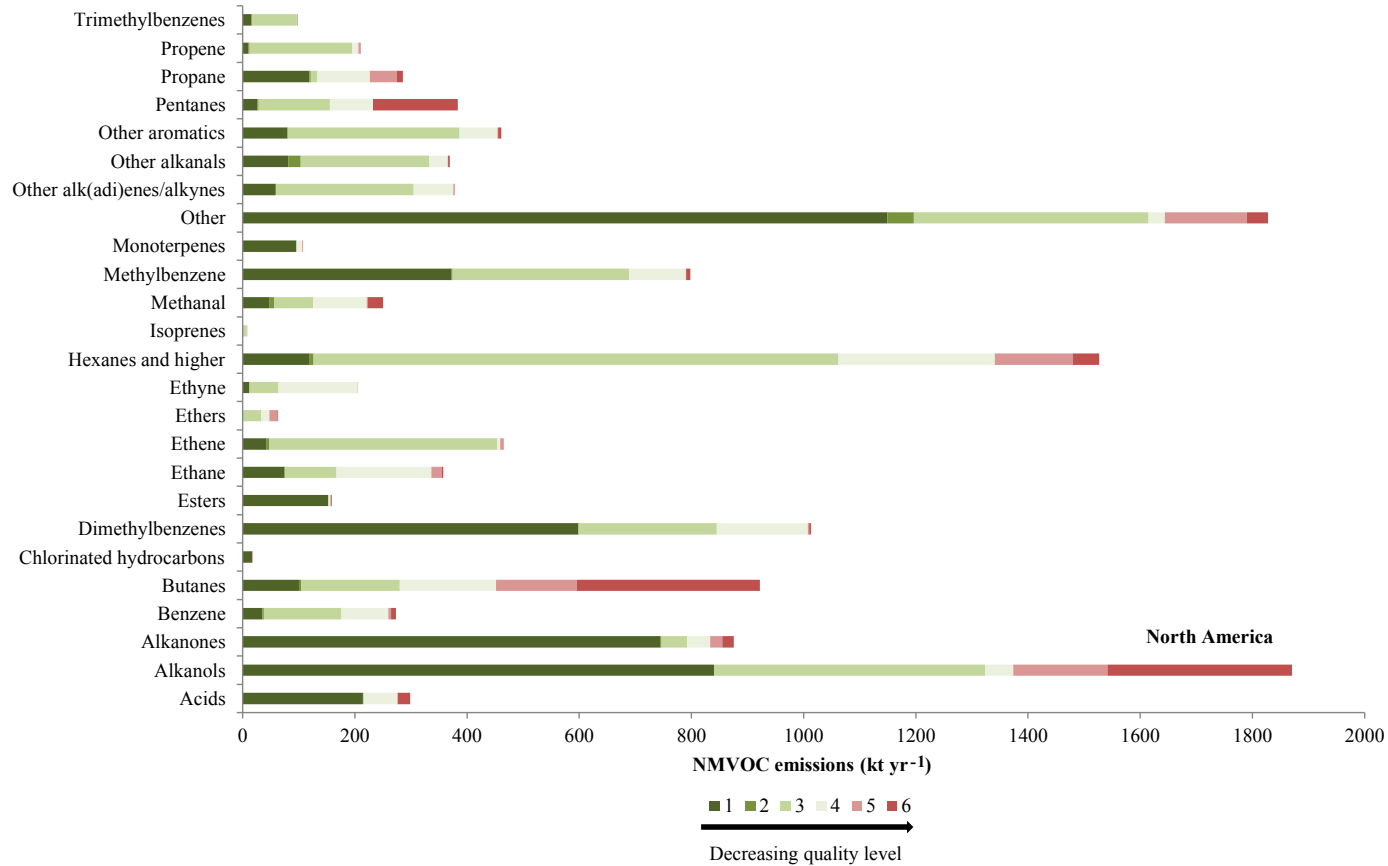

Figure 13. Emissions of 25 NMVOC groups associated with each quality code in 2010 in North America. 

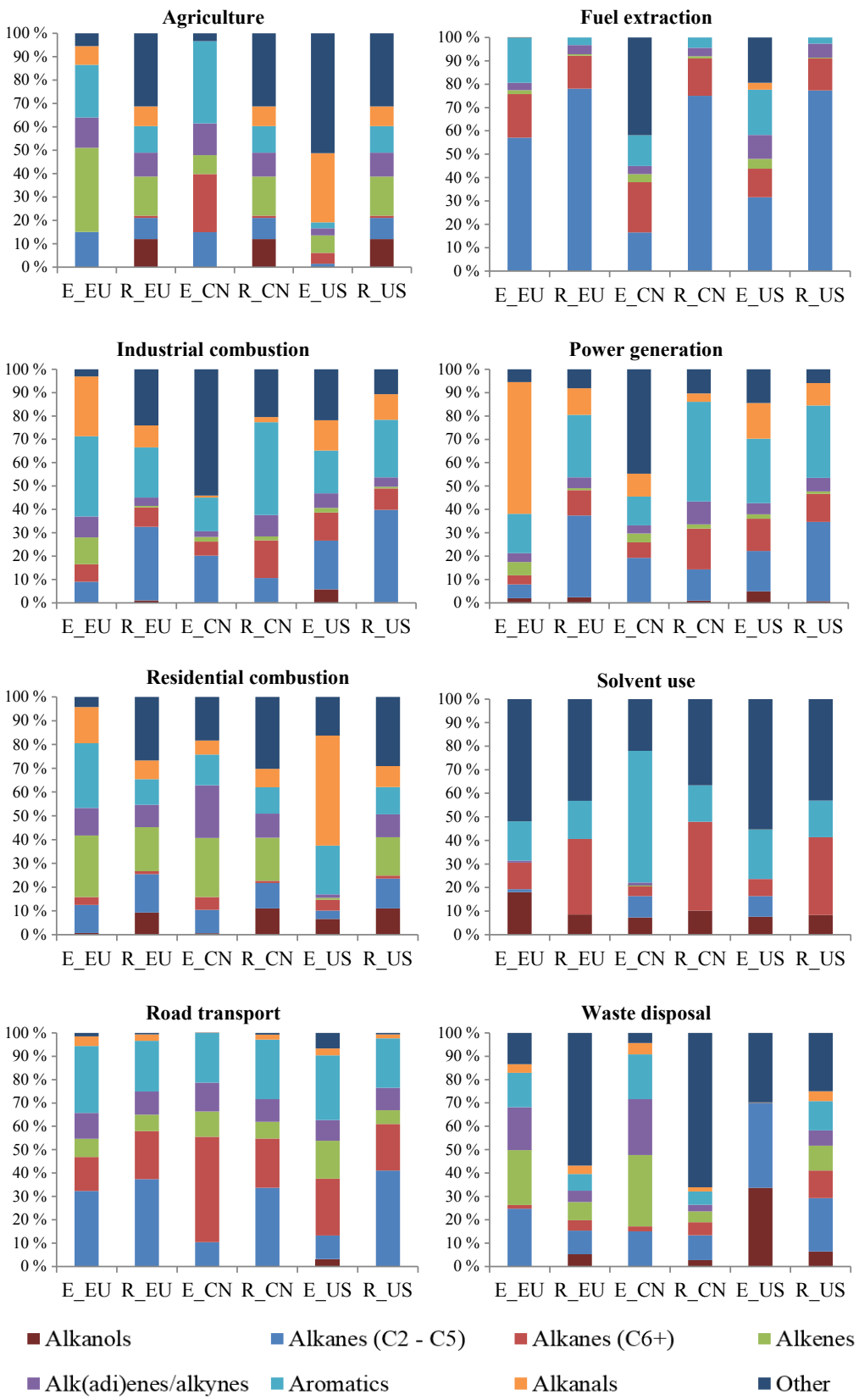

E: EDGAR R: RETRO

Figure 14. Comparison of NMVOC species composition of eight sectors between EDGAR (E) and RETRO (R) data sets for Europe (EU), China $(\mathrm{CN})$, and the United States (US) in 2000.

total NMVOC emissions in the United States in 2010 according to the EDGAR database.

\section{Conclusions and outlook}

In this study, a global speciated NMVOC emission data set is developed by compiling and allocating region- and sourcespecific NMVOC speciation profiles to the EDGAR v4.3.2 emission inventory, which can serve as input data for CTMs and related health impact assessments. This, to the authors' knowledge, represents the first compilation of global speciated NMVOC grid maps with high resolution. Quality codes are assigned to each matching to indicate appropriateness and completeness. Individual NMVOC species in different profiles are aggregated to 25 species groups as proposed by the GEIA initiative to enhance the usability of the data set for CTMs. By integrating the speciation profiles into the EDGAR database, species time series for the period 1970 
2012 and global grid maps of $0.1^{\circ} \times 0.1^{\circ}$ are produced by sector and species. Trends in NMVOC emissions from 1970 to 2012 are analysed by region. Case studies for Germany and the UK show that total NMVOC emissions of transport and residential sectors decreased dramatically from the late 1980 s to recent years in both countries. The implementation of transport emission control strategies and the fuel shift from coal to cleaner fuels (oil, natural gas, and solid biomass) have led to increased shares of alkanes and alkanals and a decreased share of aromatics. A quality assessment is performed to discuss the uncertainties of the generated data set by region, source, and species. Comparison of the generated emission data set with the RETRO emission inventory shows good agreement for sectors in Europe and the United States and a higher regional specificity of the data set produced.

Due to the unavailability of measurements and literature regarding local NMVOC source profiles, regionally specific profiles for regions other than Europe, Asia, and North America (e.g. Africa, South America) could not be compiled. Instead, a "world average" profile set has been generated that is recommended for use in these regions. Six levels of mapping quality codes are assigned when speciation profiles are mapped to a certain EDGAR process, with quality codes 5 and 6 representing fuzzy matches due to the lack of specific profiles. These represent the priority areas for further improvement.

Data availability. The speciated NMVOC emissions data are available as time series and global grid maps on the EDGAR website (http://edgar.jrc.ec.europa.eu/overview.php?v=432_VOC_ spec) and on the JRC data portal (time series: http://data.europa.eu/ 89h/jrc-edgar-edgar_v432_voc_spec_timeseries; grid maps: http: //data.europa.eu/89h/jrc-edgar-edgar_v432_voc_spec_gridmaps).

\section{The Supplement related to this article is available online at https://doi.org/10.5194/acp-17-7683-2017-supplement.}

Competing interests. The authors declare that they have no conflict of interest.

Acknowledgements. This work was financed through the project "Provision of Support for Atmospheric composition modellingCase Study-Mapping of NMVOC Emissions in the EDGAR system" by the Joint Research Centre, European Commission. We would like to thank Erika von Schneidemesser of the Institute for Advanced Sustainability Studies and Frank Dentener of the European Commission, Joint Research Centre, Directorate for Sustainable Resources, Food Security Unit, for their insights and suggestions on species aggregation.

Edited by: Q. Zhang

Reviewed by: W. Wei and one anonymous referee

\section{References}

Cai, C., Geng, F., Tie, X., Yu, Q., and An, J.: Characteristics and source apportionment of VOCs measured in Shanghai, China, Atmos. Environ., 44, 5005-5014, https://doi.org/10.1016/j.atmosenv.2010.07.059, 2010.

Cai, H. and Xie, S. D.: Tempo-spatial variation of emission inventories of speciated volatile organic compounds from onroad vehicles in China, Atmos. Chem. Phys., 9, 6983-7002, https://doi.org/10.5194/acp-9-6983-2009, 2009.

Carter, W. P. L.: Development of a database for chemical mechanism assignments for volatile organic emissions, J. Air Waste Manage. Assoc., 65, 1171-1184, https://doi.org/10.1080/10962247.2015.1013646, 2015.

Chan, L.-Y., Chu, K.-W., Zou, S.-C., Chan, C.-Y., Wang, X.-M., Barletta, B., Blake, D. R., Guo, H., and Tsai, W.-Y.: Characteristics of nonmethane hydrocarbons (NMHCs) in industrial, industrial-urban, and industrial-suburban atmospheres of the Pearl River Delta (PRD) region of south China, J. Geophys. Res., 111, D11304, https://doi.org/10.1029/2005JD006481, 2006.

Coll, I., Rousseau, C., Barletta, B., Meinardi, S., and Blake, D. R.: Evaluation of an urban NMHC emission inventory by measurements and impact on CTM results, Atmos. Environ., 44, 38433855, https://doi.org/10.1016/j.atmosenv.2010.05.042, 2010.

Crippa, M., Janssens-Maenhout, G., Dentener, F., Guizzardi, D., Sindelarova, K., Muntean, M., Van Dingenen, R., and Granier, C.: Forty years of improvements in European air quality: regional policy-industry interactions with global impacts, Atmos. Chem. Phys., 16, 3825-3841, https://doi.org/10.5194/acp-163825-2016, 2016.

Dore, C. J., Watterson, J. D., Murrells, T. P., Passant, N. R., Hobson, M. M., Baggott, S. L., Thistlethwaite, G., Goodwin, J. W. L., King, K. R., Adams, M., Walker, C., Downes, M. K., Coleman, P. J., Stewart, R. A., Wagner, A., Sturman, J., Conolly, C., Lawrence, H., Li, Y., Jackson, J., Bush, T., Grice, S., and Brophy, N.: UK Emissions of Air Pollutants 1970 to 2004, National Atmospheric Emissions Inventory, 2006.

EEA: EMEP/EEA air pollutant emission inventory guidebook - 2013, European Environment Agency, Technical report no. 12/2013, 2013.

EEA: Air quality in Europe - 2015 report, European Environment Agency, EEA report no. 5/2015, available from: http://www.eea. europa.eu//publications/air-quality-in-europe-2015 (last access: 6 March 2016), 2015.

FAOSTAT: Statistics Division of the Food Agricultural Organisation (FAO), Live animal numbers, crop production, total nitrogen fertiliser consumption statistics till 2012, 2014.

Fu, X. Q., Weng, Y. B., Qian, F. Z., Ye, W. B., Jin, Y. X., and Chen, Y. Y.: Study of the VOC source profile and benzene compounds emission of various motor vehicles, Acta Sci. Circumstantise, 28, 1056-1062, 2008.

Guenther, A. B., Jiang, X., Heald, C. L., Sakulyanontvittaya, T., Duhl, T., Emmons, L. K., and Wang, X.: The Model of Emissions of Gases and Aerosols from Nature version 2.1 (MEGAN2.1): an extended and updated framework for modeling biogenic emissions, Geosci. Model Dev., 5, 1471-1492, https://doi.org/10.5194/gmd-5-1471-2012, 2012.

He, Q. S., Wang, X. M., and Zhao, L. R.: Preliminary study on profiles of VOCs emitted from coking, Environ. Monit. China, 21, 61-64, available from: https: 
//www.researchgate.net/publication/284772965_Preliminary_ study_on_profiles_of_VOCs_emitted_from_coking (last access: 1 March 2016), 2005.

He, Z., Zhang, Y., and Wei, W.: Formaldehyde and VOC emissions at different manufacturing stages of wood-based panels, Build. Environ., 47, 197-204, https://doi.org/10.1016/j.buildenv.2011.07.023, 2012.

Hsu, Y., Divita, F., and Dorn, J.: SPECIATE Version 4.4 Database Development Documentation, Washington, DC, 2014.

IEA: Energy Statistics of OECD and Non-OECD Countries, Online data service, http://data.iea.org (last access: 1 March 2016), 2014.

Janssens-Maenhout, G., Crippa, M., Guizzardi, D., Dentener, F., Muntean, M., Pouliot, G., Keating, T., Zhang, Q., Kurokawa, J., Wankmüller, R., Denier van der Gon, H., Kuenen, J. J. P., Klimont, Z., Frost, G., Darras, S., Koffi, B., and Li, M.: HTAP_v2.2: a mosaic of regional and global emission grid maps for 2008 and 2010 to study hemispheric transport of air pollution, Atmos. Chem. Phys., 15, 11411-11432, https://doi.org/10.5194/acp-15-11411-2015, 2015.

Janssens-Maenhout, G., Muntean, M., Crippa, M., Guizzardi, D., Schaaf, E., Dentener, F., Pagliari, V., Olivier, J. G. J., Peters, J. A. H. W., van Aardenne, J. A., Monni, S., Doering, U., and Petrescu, A. M. R.: The 1970-2012 emissions atlas of EDGARv4.3.2: Part I - Greenhouse gas emissions, Earth Syst. Sci. Data Discuss., in preparation, 2017.

Jia, J., Huang, C., Chen, C., Chen, M., Wang, H., Shao, M., Dong, Y., Dai, P., Xie, S., Lu, J., and Huang, H.: Emission characterization and ambient chemical reactivity of volatile organic compounds (VOCs) from coking processes, Acta Sci. Circumstantiae, 29, 905-912, available from: https: //www.researchgate.net/publication/279601112_Emission_ characterization_and_ambient_chemical_reactivity_of_volatile_ organic_compounds_VOCs_from_coking_processes (last access: 1 March 2016), 2009.

KBA: Fahrzeugzulassung (FZ) Bestand an Kraftfahrzeugen nach Emissionen und Kraftstoffen, Kraftfahrt-Bundesamt, 2010.

Klimont, Z., Streets, D. G., Gupta, S., Cofala, J., Lixin, F., and Ichikawa, Y.: Anthropogenic emissions of non-methane volatile organic compounds in China, Atmos. Environ., 36, 1309-1322, https://doi.org/10.1016/S1352-2310(01)00529-5, 2002.

Kühlwein, J., Wickert, B., Trukenmüller, A., Theloke, J., and Friedrich, R.: Emission modelling in high spatial and temporal resolution and calculation of pollutant concentrations for comparisons with measured concentrations, Atmos. Environ., 36, 718, https://doi.org/10.1016/S1352-2310(02)00209-1, 2002.

Lau, A. K. H., Yuan, Z., Yu, J. Z., and Louie, P. K. K.: Source apportionment of ambient volatile organic compounds in Hong Kong, Sci. Total Environ., 408, 4138-49, https://doi.org/10.1016/j.scitotenv.2010.05.025, 2010.

Li, M., Zhang, Q., Streets, D. G., He, K. B., Cheng, Y. F., Emmons, L. K., Huo, H., Kang, S. C., Lu, Z., Shao, M., Su, H., Yu, X., and Zhang, Y.: Mapping Asian anthropogenic emissions of non-methane volatile organic compounds to multiple chemical mechanisms, Atmos. Chem. Phys., 14, 5617-5638, https://doi.org/10.5194/acp-14-5617-2014, 2014.

Li, X., Wang, S., Duan, L., and Hao, J.: Characterization of nonmethane hydrocarbons emitted from open burning of wheat straw and corn stover in China, Environ. Res. Lett., 4, 44015, https://doi.org/10.1088/1748-9326/4/4/044015, 2009.

Liu, Y., Shao, M., Fu, L., Lu, S., Zeng, L., and Tang, D.: Source profiles of volatile organic compounds (VOCs) measured in China: Part I, Atmos. Environ., 42, 6247-6260, https://doi.org/10.1016/j.atmosenv.2008.01.070, 2008.

Lu, S. H., Bai, Y. H., Zhang, G. S., and Ma, J.: Study on the Characteristics of VOCs Source Profiles of Vehicle Exhaust and Gasoline Emission, Acta Sci. Nat., 39, 507-511, 2003.

Olivier, J. G. J., Bouwman, A. F., van der Maas, C. W. M., Berdowski, J. J. M., Veldt, C., Bloos, J. P. J., Visschedijk, A. J. H., Zandveld, P. Y. J., and Haverlag, J. L.: Description of EDGAR Version 2.0: A set of global emission inventories of greenhouse gases and ozone-depleting substances for all anthropogenic and most natural sources on a per country basis and on $1^{\circ} \times 1^{\circ}$ grid, National Institute of Public Health and the Environment (RIVM), Bilthoven, Report no. 771060002/TNO-MEP report no. R96/119, 1996.

Passant, N. R.: Speciation of UK emissions of non-methane volatile organic compounds, AEAT/ENV/R/0545, 2002.

Piccot, S. D., Watson, J. J., and Jones, J. W.: A global inventory of volatile organic compound emissions from anthropogenic sources, J. Geophys. Res. Atmos., 97, 9897-9912, https://doi.org/10.1029/92JD00682, 1992.

Schultz, M. G., Backman, L., Balkanski, Y., Bjoerndalsaeter, S., Brand, R., Burrows, J. P., Dalsoeren, S., de Vasconcelos, M., Grodtmann, B., and Hauglustaine, D. A.: REanalysis of the TROpospheric chemical composition over the past 40 years (RETRO) - A long-term global modeling study of tropospheric chemistry, available at: http://retro-archive.iek. fz-juelich.de/data/documents/reports (last access: January 2017), 2007.

Theloke, J. and Friedrich, R.: Compilation of a database on the composition of anthropogenic VOC emissions for atmospheric modeling in Europe, Atmos. Environ., 41, 4148-4160, https://doi.org/10.1016/j.atmosenv.2006.12.026, 2007.

UK IIR: UK Informative Inventory Report (1990 to 2015), Final Version (v1.0), available from: https://uk-air.defra.gov.uk/assets/ documents/reports/cat07/1703161205_GB_IIR_2017_Final_v1. 0.pdf, last access: 21 March 2017.

UN STATS (UN Statistics Division): Industrial Commodity Production Statistics 1970-2013, http://unstats.un.org/unsd/industry/ publications.asp, 2014.

USGS: US Geological Survey Minerals Yearbook, US Geological Survey, Reston, Virginia, http://mninerals.usgs.gov/minerals/ pubs/commodity, 2014.

Vautard, R.: Paris emission inventory diagnostics from ESQUIF airborne measurements and a chemistry transport model, J. Geophys. Res., 108, 8564, https://doi.org/10.1029/2002JD002797, 2003.

Wang, H.: Source Profiles and Chemical Reactivity of Volatile Organic Compounds from Solvent Use in Shanghai, China, Aerosol Air Qual. Res., 14, 301-310, https://doi.org/10.4209/aaqr.2013.03.0064, 2014.

Wei, W., Wang, S., Chatani, S., Klimont, Z., Cofala, J., and Hao, J.: Emission and speciation of non-methane volatile organic compounds from anthropogenic sources in China, Atmos. Environ., 42, 4976-4988, https://doi.org/10.1016/j.atmosenv.2008.02.044, 2008. 
Wei, W., Wang, S., Hao, J., and Cheng, S.: Trends of chemical speciation profiles of anthropogenic volatile organic compounds emissions in China, 2005-2020, Front. Environ. Sci. Eng., 8, 1-15, https://doi.org/10.1007/s11783-012-0461-4, 2012.

Weichenthal, S., Kulka, R., Bélisle, P., Joseph, L., Dubeau, A., Martin, C., Wang, D., and Dales, R.: Personal exposure to specific volatile organic compounds and acute changes in lung function and heart rate variability among urban cyclists, Environ. Res., 118, 118-23, https://doi.org/10.1016/j.envres.2012.06.005, 2012.
Yuan, B., Shao, M., Lu, S., and Wang, B.: Source profiles of volatile organic compounds associated with solvent use in Beijing, China, Atmos. Environ., 44, 1919-1926, https://doi.org/10.1016/j.atmosenv.2010.02.014, 2010. 